Computational and Experimental Investigation of the Detection of HO2 Radical and the Products of Its Reaction with Cyclohexene Ozonolysis Derived RO2 Radicals by an lodide-Based Chemical Ionization Mass Spectrometer

\title{
lyer, Siddharth
}

2017-09-14

lyer , S , He , X , Hyttinen , N , Kurten , T \& Rissanen , M P 2017 , ' Computational and Experimental Investigation of the Detection of $\mathrm{HO} 2$ Radical and the Products of Its Reaction with Cyclohexene Ozonolysis Derived RO2 Radicals by an lodide-Based Chemical Ionization Mass Spectrometer ' , Journal of Physical Chemistry A, vol. 121 , no. 36 , pp. 6778-6789 . https://doi.org/10.1021/acs.jpca.7b01588

http://hdl.handle.net/10138/307395

https://doi.org/10.1021/acs.jpca.7b01588

acceptedVersion

Downloaded from Helda, University of Helsinki institutional repository.

This is an electronic reprint of the original article.

This reprint may differ from the original in pagination and typographic detail.

Please cite the original version. 
This document is confidential and is proprietary to the American Chemical Society and its authors. Do not copy or disclose without written permission. If you have received this item in error, notify the sender and delete all copies.

\section{Computational and Experimental Investigation of the Detection of $\mathrm{HO}_{2}$ Radical and the Products of Its Reaction with Cyclohexene Ozonolysis Derived $\mathrm{RO}_{2}$ Radicals by an Iodide-Based Chemical Ionization Mass Spectrometer}

\begin{tabular}{|r|l|}
\hline Journal: & The Journal of Physical Chemistry \\
\hline Manuscript ID & jp-2017-01588j.R1 \\
\hline Manuscript Type: & Article \\
\hline Date Submitted by the Author: & n/a \\
\hline Complete List of Authors: & $\begin{array}{l}\text { Iyer, Siddharth; University of Helsinki, Department of molecular sciences } \\
\text { He, Xucheng; University of Helsinki, Department of Physics } \\
\text { Hyttinen, Noora; University of Helsinki, Chemistry } \\
\text { Kurtén, Theo; University of Helsinki, Department of Chemistry } \\
\text { Rissanen, Matti; University of Helsinki, Physics }\end{array}$ \\
\hline
\end{tabular}

\section{SCHOLARONE" \\ Manuscripts}




\title{
Computational and Experimental Investigation of
} the Detection of $\mathrm{HO}_{2}$ Radical and the Products of Its Reaction with Cyclohexene Ozonolysis Derived $\mathrm{RO}_{2}$ Radicals by an lodide-Based

\section{Chemical Ionization Mass Spectrometer}

Siddharth lyer, ${ }^{*, \dagger}$ Xucheng He, ${ }^{\ddagger}$ Noora Hyttinen, ${ }^{\dagger}$ Theo Kurtén, ${ }^{,}, \dagger$ and Matti P.

\author{
Rissanen \\ Department of Chemistry, University of Helsinki, Finland, and Department of Physics, \\ University of Helsinki, Finland \\ E-mail: siddharth.iyer@helsinki.fi; theo.kurten@helsinki.fi
}

\begin{abstract}
The $\mathrm{HO}_{2}$ radical is an important atmospheric molecule that can potentially influence the termination of autoxidation processes of volatile organic compounds (VOCs) that lead to the formation of highly oxygenated multifunctional compounds (HOMs). In this work, we demonstrate the direct detection of the $\mathrm{HO}_{2}$ radical using an iodide-based chemical ionization mass spectrometer (iodide-CIMS). Expanding on the previously established correlation between molecule-iodide binding enthalpy and iodide-CIMS
\end{abstract}

\footnotetext{
${ }^{*}$ To whom correspondence should be addressed

†Department of Chemistry, University of Helsinki

${ }^{\ddagger}$ Department of Physics, University of Helsinki
} 
instrument sensitivity, the experimental detection of the $\mathrm{HO}_{2}$ radical was preceded by the quantum chemical calculation of the $\mathrm{HO}_{2}{ }^{*} \mathrm{I}^{-}$cluster $(\mathrm{PBE} /$ aug-cc-pVTZ-PP level), which showed a reasonably strong binding enthalpy of $21.60 \mathrm{kcal} / \mathrm{mol}$. Cyclohexene ozonolysis intermediates and closed-shell products were next detected by the iodide-CIMS. The ozone-initiated cyclohexene oxidation mechanism was perturbed by the introduction of the $\mathrm{HO}_{2}$ radical, leading to the formation of closed-shell hydroperoxides. The experimental investigation once again followed the initial computational molecule-iodide binding enthalpy calculations. The quantum chemical calculations were performed at the PBE/aug-cc-pVTZ-PP level for radicals and DLPNOCCSD(T)/def2QZVPP//PBE/aug-cc-pVTZ-PP level for the closed-shell products. A comparison between the iodide-CIMS and nitrate-CIMS spectra with identical measurement steps revealed that the iodide-CIMS was able to detect the low-oxidized (O:C ratio 0.5 and 0.66 ) cyclohexene ozonolysis monomer products more efficiently than nitrate-CIMS. Higher-oxidized monomers (O:C ratio 1 to 1.5) were detected equally well by both methods. An investigation of dimers showed that both iodide- and nitrate-CIMS were able to detect the dimer compositions possibly formed from reactions between the peroxy radical monomers considered in this study. Additionally, iodide-CIMS detected organic ions that were formed by a previously suggested mechanism of dehydroxylation of peroxy acids (and deoxygenation of acyl peroxy radicals) by $\mathrm{H}_{2} \mathrm{O}^{*} \mathrm{I}^{-}$clusters. These mechanisms were computationally verified.

\section{Introduction}

The $\mathrm{HO}_{2}$ radical is an important molecule that plays a critical role in the photoxidation cycles of the atmosphere. It is especially important in the production of $\mathrm{NO}_{2}$. A product of $\mathrm{OH}$ radical reaction with volatile organic compounds (VOCs) in the atmosphere, $\mathrm{HO}_{2}$ reacts with $\mathrm{NO}$ to form $\mathrm{NO}_{2}$, a key step in the formation of tropospheric ozone and thereby also the $\mathrm{OH}$ radical. In addition, reaction with $\mathrm{HO}_{2}$ is an important sink for organic peroxy radicals $\left(\mathrm{RO}_{2}\right)$ formed from oxidation reactions of VOCs. ${ }^{1}$ Additional peroxy radical sink reactions 
include bimolecular reactions with $\mathrm{NO}_{x}$ and other organic peroxy radicals. In the absence of a sink reaction, some peroxy radical species may undergo intra-molecular hydrogen shifts, followed by autoxidation to form highly-oxidized multifunctional compounds (HOMs). ${ }^{2-5}$ These HOMs have been suggested to play a key role in SOA formation in the atmosphere. ${ }^{6}$ Their low volatility allows them to condense onto particles. ${ }^{7,8}$

Chemical ionization mass spectrometry (CIMS) with nitrate as the reagent ion has been an important tool in the detection of atmospherically relevant HOMs. ${ }^{4,5,9,10}$ However, nitrate is a highly selective reagent ion, and is unsuitable for ionizing the lower-oxidized VOCs. According to current knowledge, nitrate usually requires two hydrogen-bond donating groups in a sample molecule to bind efficiently. The molecule-nitrate complex binding energy must be higher than that of the nitrate dimer $\left(\mathrm{HNO}_{3} \mathrm{NO}_{3}^{-}\right)$for the complex to be detected efficiently. ${ }^{11}$ The $\mathrm{HO}_{2}$ radical, for example, is not detected by a nitrate-CIMS. The use of iodide anion as the reagent ion, on the other hand, has been reported to work well with the low-oxidized organic acids. ${ }^{12-14}$

Iodide has a large negative mass defect, which is the difference between the nominal (integer) mass and the exact mass of a molecule. This helps differentiate between iodide-clustered ions and other contaminant ions in the mass spectrum. ${ }^{13}$ Iodide has also been observed to react with peroxy acids in the presence of water, forming carboxylate ions. ${ }^{13,15,16}$ These ions appear in the spectrum with a positive mass defect. When coupled with a high resolution mass spectrometer, these properties of the iodide ion aid to separate contaminant peaks and helps in the identification of the composition and structure of the molecules corresponding to the peaks in an iodide-CIMS spectrum.

The detection of the $\mathrm{HO}_{2}$ radical using a quadrupole mass spectrometer (QMS) with iodide as the reagent ion has been explored previously. ${ }^{17}$ A QMS generally offers only unit mass resolution, which makes it difficult to separate peaks that are within one mass unit of each other. 
An investigation using an iodide-based high-resolution Time-of-Flight CIMS (HR-ToF-CIMS) by Sanchez et al. ${ }^{18}$ revealed that the $\mathrm{HO}_{2}$ radical can be detected by an iodide-CIMS. In this work, in addition to the direct experimental detection of the $\mathrm{HO}_{2}$ radical, we use the model proposed previously in Iyer et al. ${ }^{14}$ which is based on the comparison between experimentally determined sensitivities and quantum chemically calculated molecule- $\mathrm{I}^{-}$complex binding enthalpies. We have also experimentally and computationally investigated the dependence of the $\mathrm{HO}_{2}$ signal on the relative humidity. Furthermore, cyclohexene ozonolysis intermediates and products were experimentally and theoretically investigated - particularly, the formation of closed-shell hydroperoxide products from the $\mathrm{RO}_{2}+\mathrm{HO}_{2}$ reaction. The experiments were repeated with nitrate as the reagent ion to draw a comparison between the performance of the two ionization methods for a set of radicals and closed-shell products from cyclohexene ozonolysis. Finally, the mechanism for forming the experimentally detected dehydroxylated organic ions were investigated using quantum chemical methods.

\section{Experimental section}

\section{Laboratory Experiment Details}

The experiments were performed at room temperature $(\mathrm{T}=293 \pm 3 \mathrm{~K})$ and atmospheric pressure. $\mathrm{N}_{2}$ and synthetic air $\left(\mathrm{N}_{2}+\mathrm{O}_{2}\right)$ were used as carrier gas flows. The iodide-based chemical ionization inlet contains an ambient pressure ion molecule region (IMR), followed by an atmospheric pressure interface (APi-TOF) which consists of three chambers - two with ion-guiding quadrupoles and a third with ion lenses which guide the ionized molecules to the TOF analyzer. The APi-TOF has been described in detail previously by Junninen et al., ${ }^{19}$ and the design of the CI-inlet by Kurtén et al. ${ }^{20}$ The sample is drawn through a 3/4" stainless steel tube with a flow rate of about $9.5 \mathrm{lpm}$. Iodide ions were generated by exposing ethyliodide $\left(\mathrm{C}_{2} \mathrm{H}_{5} \mathrm{I}\right)$ containing $\mathrm{N}_{2}$ flow (about $20 \mathrm{lpm}$ ) to an x-ray source (Hamamatsu L9490). This sheath flow is introduced into the IMR region concentric to the sample flow. 
The iodide ions are deflected towards the sample flow by an electric field. The interaction time between the ions and the sample is approximately $200 \mathrm{~ms}$.

Ionization occurs mainly via adduct formation where $\mathrm{I}^{-}$anions cluster with the sample molecule X:

$$
X+I^{-} \rightarrow X * I^{-}
$$

The molecule-I- $\mathrm{I}^{-}$complex is directed towards the TOF analyzer via a critical orifice that limits the flow rate to $\sim 0.8 \mathrm{lpm}$. A detailed explanation of the differentially pumped chambers and quadrupole ion guides that make up the intermediate region between the inlet and the TOF analyzer sections of the mass spectrometer is provided by Junninen et al. ${ }^{19}$

The detection of the $\mathrm{HO}_{2}$ radical using an iodide-CIMS was investigated in this study. The generation of the $\mathrm{HO}_{2}$ radical in the laboratory was achieved by photolyzing water vapor at $184.9 \mathrm{~nm}\left(\mathrm{Hg}\right.$ PenRay $\left.{ }^{\mathrm{TM}}\right)$ in the presence of $\mathrm{O}_{2}$, which involves the following reaction steps:

$$
\begin{gathered}
\mathrm{H}_{2} \mathrm{O} \stackrel{h \gamma}{\rightarrow} \mathrm{H}+\mathrm{OH} \\
\mathrm{H}+\mathrm{O}_{2} \rightarrow \mathrm{HO}_{2}
\end{gathered}
$$

The water content of the $\mathrm{N}_{2}$ flow was controlled by passing a part of the gas through a water reservoir. The 2-meter long and 1-inch in diameter quartz flow tube used in the experiments is transparent to UV light at the wavelength range of the mercury $(\mathrm{Hg})$ lamp. Synthetic air was used to provide the necessary oxygen to produce the $\mathrm{HO}_{2}$ radical (reaction 3 ). The air flow was shielded from the UV light by flowing it through a borosilicate tube placed concentrically inside the quartz flow tube. The borosilicate tube is opaque to the $184.9 \mathrm{~nm} \mathrm{UV}$ light that photodissociates $\mathrm{H}_{2} \mathrm{O}$. Care was taken to ensure that the borosilicate tube was longer than the region of the flow tube that was exposed to the UV light. The photodissociated hydrogen atom from reaction 2 reacts with the $\mathrm{O}_{2}$ emerging from the end of the borosilicate tube to 
form the $\mathrm{HO}_{2}$ radical (reaction 3). A schematic of the experimental setup is provided in Fig. S3 in the SI. The $\mathrm{HO}_{2}$ radical calibration measurement was performed by recording the $\mathrm{HO}_{2}{ }^{*} \mathrm{I}^{-}$signals over a series of different humidified $\mathrm{N}_{2}$ flow rates that were UV photolyzed. $\mathrm{HO}_{2}$ radical loss channels, such as $\mathrm{HO}_{2}+\mathrm{HO}_{2}, \mathrm{HO}_{2}+\mathrm{OH}$, etc., that could affect the calibration measurement were not considered as the radical concentration was low. For the details of the calibration measurement, including the calibration curve, refer to Fig. S1 in the SI. The effect of humidity on the sensitivity of the iodide-CIMS for the studied molecules was also investigated by flowing an additional humidified flow through the borosilicate tube. In order to produce ozone by $\mathrm{O}_{2}$ photolysis at $184.9 \mathrm{~nm}$, a part of the synthetic air was flown through the UV light exposed section of the quartz tube instead of the borosilicate tube. CO was used as an $\mathrm{HO}_{2}$ signal enhancer as it converts the byproduct of the photodissociation of water, $\mathrm{OH}$, into $\mathrm{HO}_{2}$. The mechanism is as follows:

$$
\begin{gathered}
\mathrm{OH}+\mathrm{CO} \rightarrow \mathrm{H}+\mathrm{CO}_{2} \\
\mathrm{H}+\mathrm{O}_{2} \rightarrow \mathrm{HO}_{2}
\end{gathered}
$$

The use of $\mathrm{CO}$ allowed an extra measure of control over the concentrations of $\mathrm{HO}_{2}$ generated in the flow tube. The $\mathrm{HO}_{2}{ }^{*} \mathrm{I}^{-}$signals were effectively doubled with the addition of CO. Cyclohexene was added to the flow through the borosilicate tube and allowed to interact with ozone to produce the ozonolysis derived peroxy radicals investigated in this study. Details of the cyclohexene ozonolysis and $\mathrm{RO}_{2}+\mathrm{HO}_{2}$ experiments performed in this study are provided in the section S4.3 in the SI.

\section{Quantum Chemical Computations}

The computational methods have been described in detail previously in Iyer et al. ${ }^{14}$ Conformer sampling was performed using the Merck Molecular Force Field (MMFF) method implemented in the Spartan '14 program. ${ }^{21}$ The conformers were generated by varying all torsional angles 
by 120 degrees. Initial geometry optimizations were performed at the B3LYP/6-31G* level with the LACVP pseudopotential ${ }^{22,23}$ using the Spartan '14 program. Conformers with relative energies within $2 \mathrm{kcal} / \mathrm{mol}$ were chosen for higher-level optimization with the PBE functional $^{24}$ and SDD basis set with Stuttgart/Dresden pseudopotentials ${ }^{25}$ using the Gaussian 09 program. ${ }^{26}$ The PBE functional was chosen since it has been shown to work well with iodide-containing systems. ${ }^{27-29}$ To test the performance of the PBE method, the optimized geometries of formic acid clustered to $\mathrm{I}^{-}$using PBE and CCSD methods (with the aug-ccpVTZ-PP basis set) were compared in Iyer et al. ${ }^{14}$ and showed a hydrogen to iodide bond length difference of only $0.04 \AA{ }^{14}$ The most energetically favorable cluster and free molecule geometries were further optimized with the triple-zeta aug-cc-pVTZ-PP basis set. ${ }^{30}$ The pseudopotential definitions for iodide atoms were taken from the EMSL basis set library. ${ }^{31,32}$ Finally, single-point energy corrections at the DLPNO-CCSD(T)/def2-QZVPP level ${ }^{33}$ were performed using the ORCA program. ${ }^{34}$ The DLPNO-CCSD(T) method has been shown to significantly reduce the computational costs while maintaining the high-accuracy of the coupled-cluster method. ${ }^{35}$ This allows high level $\operatorname{CCSD}(\mathrm{T})$ single point corrections to be performed on large systems, such as the hydroperoxide* ${ }^{-}$clusters considered in this study. However, ORCA does not currently support DLPNO-CCSD(T) calculations for open-shell systems. Therefore, the peroxy radicals and their $\mathrm{I}^{-}$clusters were calculated at the PBE/augcc-pVTZ-PP level, without CCSD(T) single point corrections. The default ORCA parameters were changed to the ones detailed in Iyer et al. ${ }^{14}$ for the adequate treatment of iodide containing systems. Single point energy corrections at the ROHF-ROCCSD(T)-F12a/VDZPP-F12 level were performed for the $\mathrm{HO}_{2}{ }^{*} \mathrm{I}^{-}$cluster using the Molpro program version 2015.1. ${ }^{36}$

\section{Detectability v/s molecule-I ${ }^{-}$binding enthalpies for an iodide-CIMS}

A good correlation between quantum chemically calculated molecule- $\mathrm{I}^{-}$cluster binding enthalpies and experimentally determined sensitivities has been developed previously. ${ }^{14}$ The 
binding enthalpies of the $\mathrm{HO}_{2}$ radical and the HOMs studied here were calculated and the prediction of the sensitivity of an iodide-CIMS for these compounds was drawn using the model.

An important conclusion from the Iyer et al. ${ }^{14}$ study was that even computationally cheap calculations can provide important insights into the detectibility of a molecule by an iodideCIMS. This is especially important when working with molecules such as HOMs that may have 20 or more non-hydrogen atoms. Performing high level calculations that includes coupledcluster energy corrections are no longer feasible at these sizes. However, for the closed-shell $\mathrm{C}_{6} \mathrm{H}_{10} \mathrm{O}_{4,6}$ cyclohexene ozonolysis products considered in this study, the calculations could still be performed at the high DLPNO-CCSD(T)/def2QZVPP//PBE/aug-cc-pVTZ-PP level.

\section{Rate coefficients for humidity dependence calculations}

Probable loss of $\mathrm{HO}_{2}{ }^{*} \mathrm{I}^{-}$clusters to ligand-exchange reactions in high relative humidity (RH) conditions were studied using the Master Equation Solver for Multi Energy-well Reactions (MESMER) software. ${ }^{37}$ The MESMER program uses quantum chemically calculated zeropoint energies to calculate the Bartis-Widom phenemological rate coefficients of reactions studied here. ${ }^{38}$ The mathematical development of the Bartis-Widom technique is described in detail by Robertson et al. ${ }^{39}$ The reactions considered for MESMER simulations were barrier-less, and were treated using the MesmerILT method. The details of the MESMER simulations, including the simulation conditions and the values of the parameters used, are provided in section S5 in the SI.

\section{Results and Discussion}

Quantum chemical calculations showed that the $\mathrm{HO}_{2}{ }^{*} \mathrm{I}^{-}$cluster has a binding enthalpy (BE) of $21.6 \mathrm{kcal} / \mathrm{mol}$ (PBE/aug-cc-pVTZ-PP level). Based on the emperical fit proposed by Iyer 
et al., ${ }^{14}$ this would correspond to a sensitivity on the order of $0.40 \mathrm{cps} / \mathrm{ppt}$. The predicted sensitivity is mentioned here to establish the likelihood of the detection of the $\mathrm{HO}_{2}$ radical by an iodide-CIMS. After a single point energy correction at the ROHF-ROCCSD(T)-F12a/VDZPP-F12 level, the $\mathrm{HO}_{2}{ }^{*} \mathrm{I}^{-}$cluster binding enthalpy was found to be $26.49 \mathrm{kcal} / \mathrm{mol}$. This value cannot be used in the emperical fit mentioned above for a predicted sensitivity, since the model in Iyer et al. was based on calculations performed at the PBE/aug-cc-pVTZ-PP level for open-shell systems. However, the strong binding enthalpy after the more accurate CCSD(T)-F12 correction shows that the $\mathrm{HO}_{2}{ }^{*} \mathrm{I}^{-}$cluster should be detected at high sensitivity by an iodide-CIMS. The optimized free radical and $\mathrm{HO}_{2}{ }^{*} \mathrm{I}^{-}$cluster geometries are given in Fig. 1. The $\mathrm{HO}_{2}{ }^{*} \mathrm{I}^{-}$complex was experimentally detected using the iodide-CIMS at the mass 159.9027. The iodide-CIMS spectrum is shown in Fig.2 $\mathbf{a}$ and the $\mathrm{HO}_{2}{ }^{*} \mathrm{I}^{-}$peak is shown in Fig.2 b.
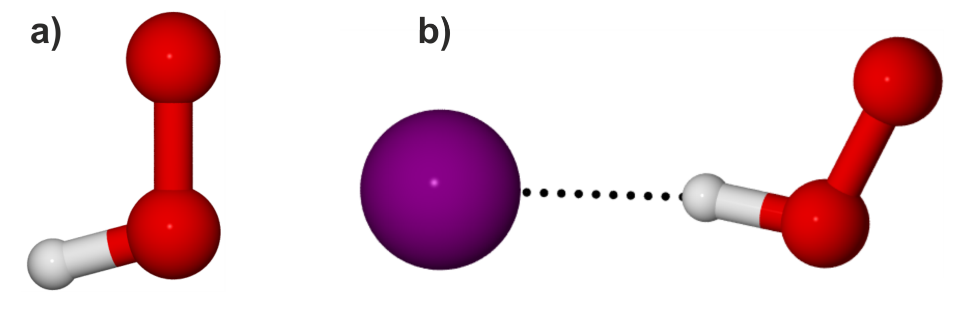

Figure 1: Free $\mathrm{HO}_{2}$ radical (a) and $\mathrm{HO}_{2}{ }^{*} \mathrm{I}^{-}$cluster (b) optimized at PBE/aug-cc-pVTZ-PP level. Color coding: Oxygen - red, hydrogen - white, iodide - purple. 


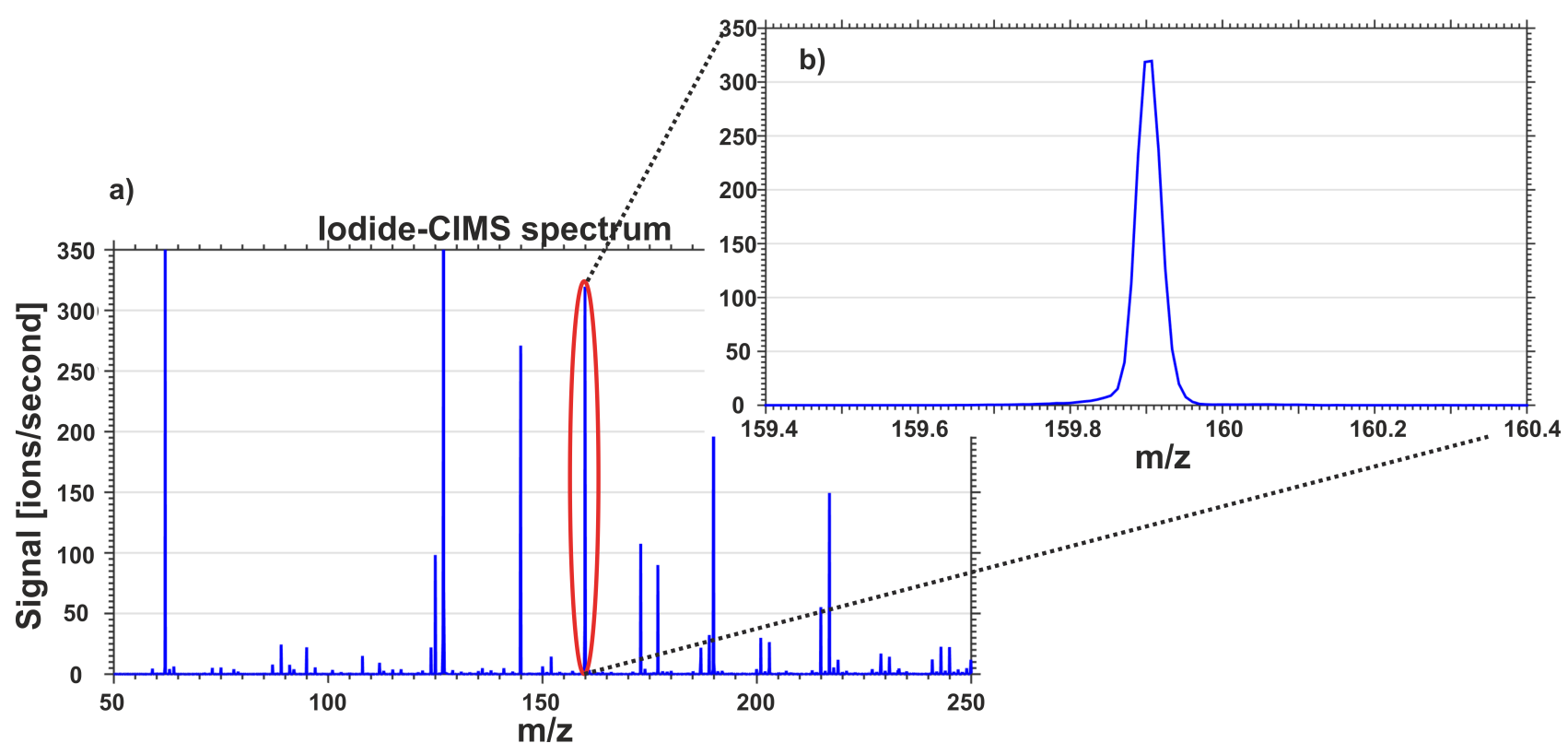

Figure 2: Iodide-CIMS spectrum (a) with the visible $\mathrm{HO}_{2}{ }^{*} \mathrm{I}^{-}$peak at mass/charge 159.9027. Inset: $\mathrm{HO}_{2}{ }^{*} \mathrm{I}^{-}$peak (b).

A high resolution fitting of the spectrum was necessary to differentiate between the $\mathrm{HO}_{2}{ }^{*} \mathrm{I}^{-}$and $\mathrm{HNO}_{3}{ }^{*} \mathrm{HSO}_{4}^{-}$clusters. Both these compounds have similar masses - 159.9027 and 159.9557 , respectively.

\section{CO dependence}

As mentioned previously, $\mathrm{CO}$ increases the $\mathrm{HO}_{2}$ radical signal by converting the other primary product of water photodissociation, the $\mathrm{OH}$ radical, into $\mathrm{HO}_{2}$. The change in $\mathrm{HO}_{2}{ }^{*} \mathrm{I}^{-}$signal with the addition of $\mathrm{CO}$ pointed to a practically quantitative conversion of $\mathrm{OH}$ into $\mathrm{HO}_{2}$, i.e. doubling of the $\mathrm{HO}_{2}$ signal (see Fig. S2 in the SI).

\section{Humidity dependence}

The effect of humidity on the $\mathrm{HO}_{2}{ }^{*} \mathrm{I}^{-}$signal was investigated by keeping the photolysis water constant and introducing an additional water flow that was shielded from the UV radiation by flowing it through an injector tube. The effect of an increase in relative humidity $(\mathrm{RH})$ on 
the $\mathrm{HO}_{2}{ }^{*} \mathrm{I}^{-}$signal is shown in Fig. 3.

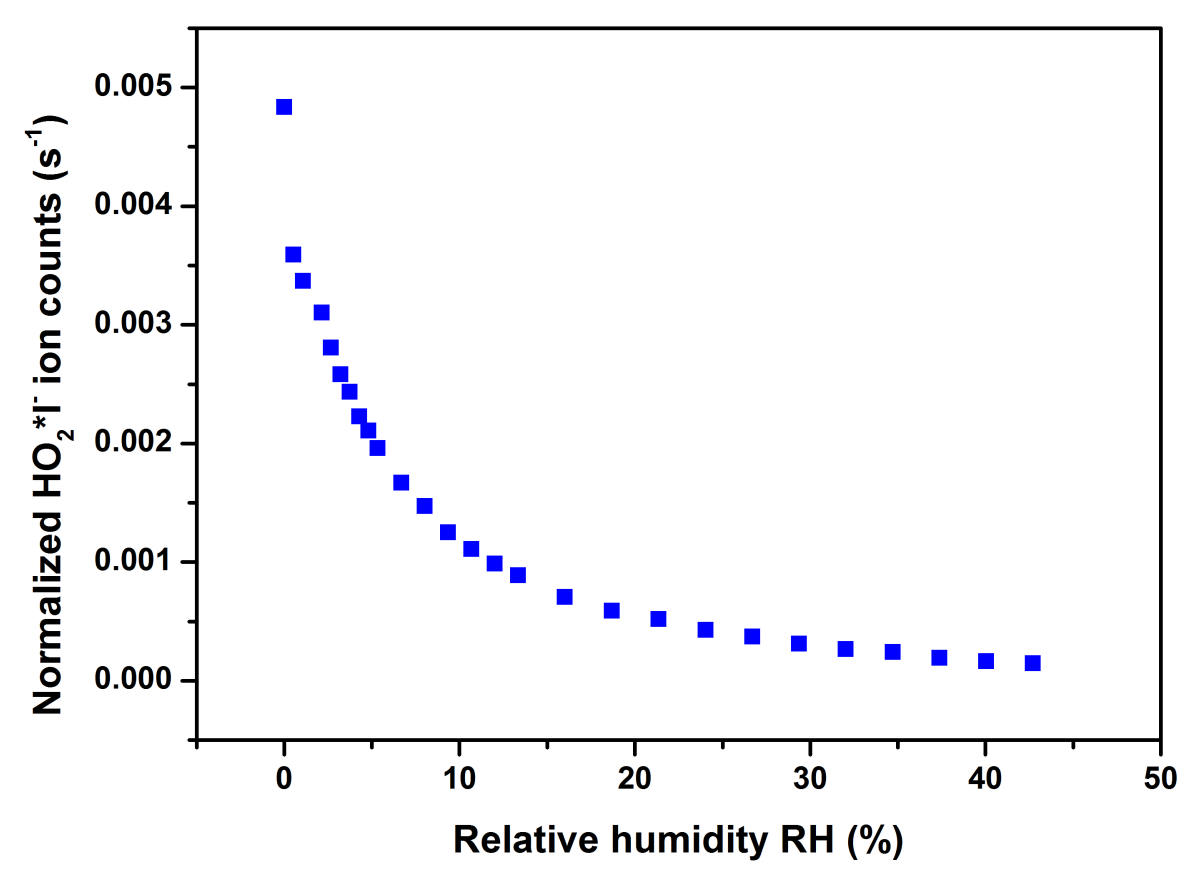

Figure 3: Dependence of the $\mathrm{HO}_{2}{ }^{*} \mathrm{I}^{-}$signal on $\mathrm{RH}$. The normalized $\mathrm{HO}_{2}{ }^{*} \mathrm{I}^{-}$ion counts suggest a strong RH dependence.

In principle, the addition of water should stabilize the $\mathrm{HO}_{2}{ }^{*} \mathrm{I}^{-}$cluster. Kinetic effects, such as energy non-accommodation, are neutralized by the increased vibrational modes and by the sacrificial-cooling effect from the evaporating water molecule. These effects play a critical role especially for small molecules, such as the $\mathrm{HO}_{2}$ radical. The effect of water on the $\mathrm{HO}_{2}{ }^{*} \mathrm{I}^{-}$clusters was investigated using MESMER software. Two simulations were considered - one, with $\mathrm{I}^{-}$as the reagent ion, and two, with $\mathrm{H}_{2} \mathrm{O}^{*} \mathrm{I}^{-}$as the reagent ion. The potential energy surfaces (PES) for the two simulations are shown in Fig. 4. With $\mathrm{H}_{2} \mathrm{O}^{*} \mathrm{I}^{-}$as the reagent ion, the $\mathrm{HO}_{2}{ }^{*} \mathrm{I}^{-}$clusters formed in the MESMER simulation (at the IMR relevant time of $200 \mathrm{~ms}$ ) was a factor of 2 higher compared to the $\mathrm{HO}_{2}{ }^{*} \mathrm{I}^{-}$clusters formed with $\mathrm{I}^{-}$as the reagent ion. That is to say that the water molecule plays an important role in stabilizing the radical-iodide cluster. However, as seen in Fig. 3, the opposite was observed. To explain 
the loss of $\mathrm{HO}_{2}{ }^{*} \mathrm{I}^{-}$signals with an increase in $\mathrm{RH}$, a third simulation was carried out to test the effect of increased water concentrations on the concentration of the already formed $\mathrm{HO}_{2}{ }^{*} \mathrm{I}^{-}$clusters. The effect of water in the monomer and dimer forms were tested. The PES is shown in Fig. 5.

a)

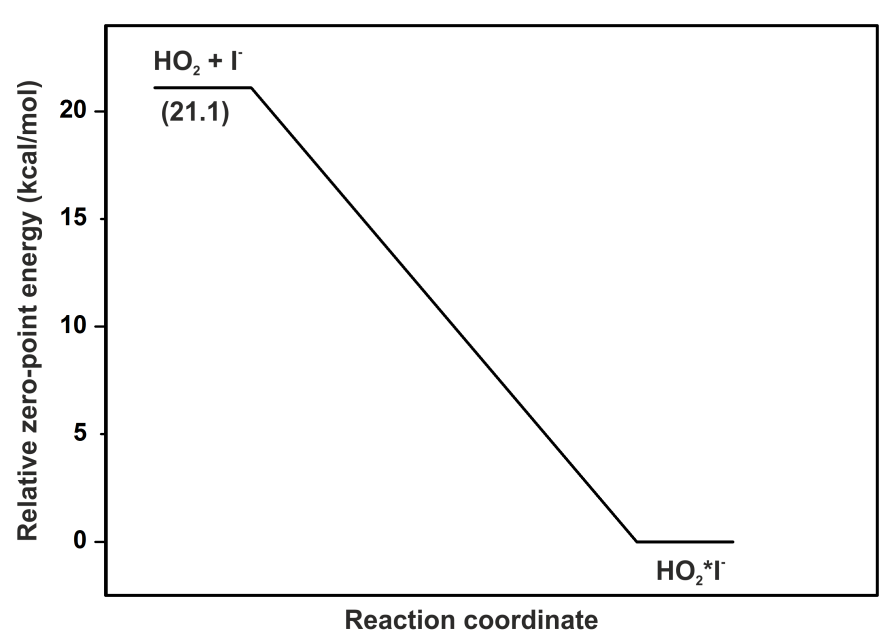

b)

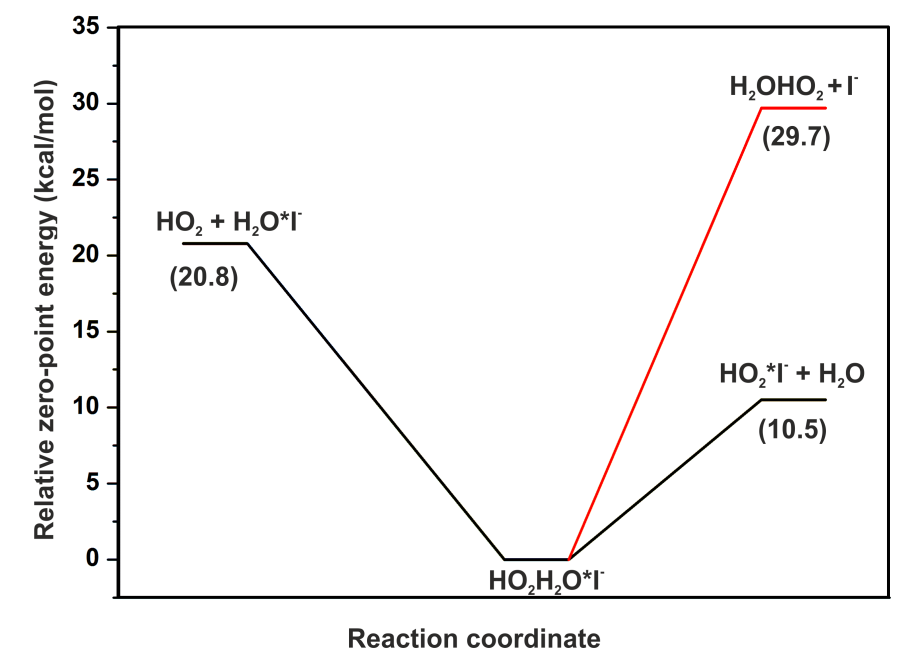

Figure 4: Potential energy surface for the formation of the $\mathrm{HO}_{2}{ }^{*} \mathrm{I}^{-}$cluster with $\mathrm{I}^{-}$(a) and $\mathrm{H}_{2} \mathrm{O}^{*} \mathrm{I}^{-}$(b) as the reagent ions. Energies were calculated at the PBE/aug-cc-pVTZ-PP level at $298 \mathrm{~K}$. 
a)

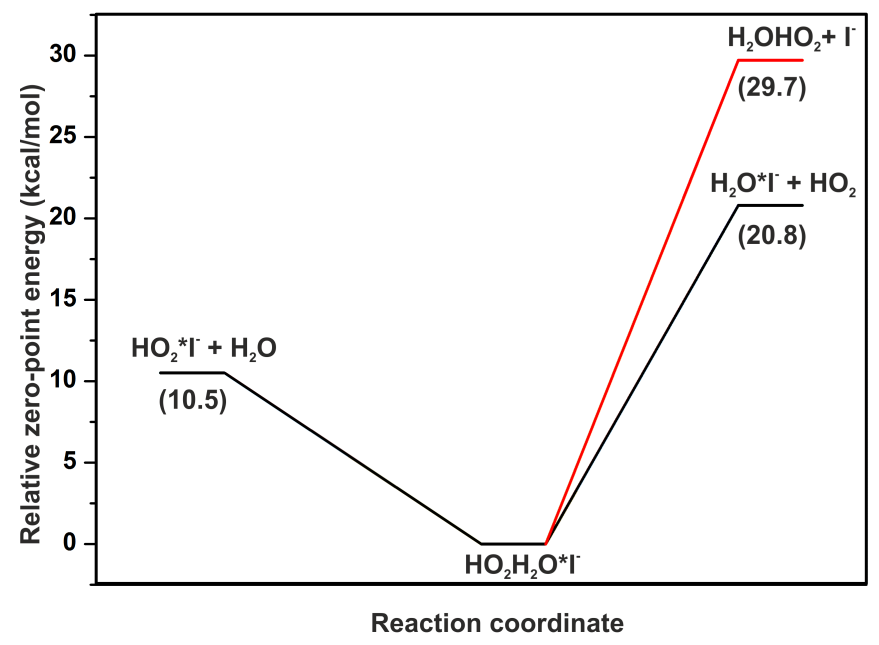

b)

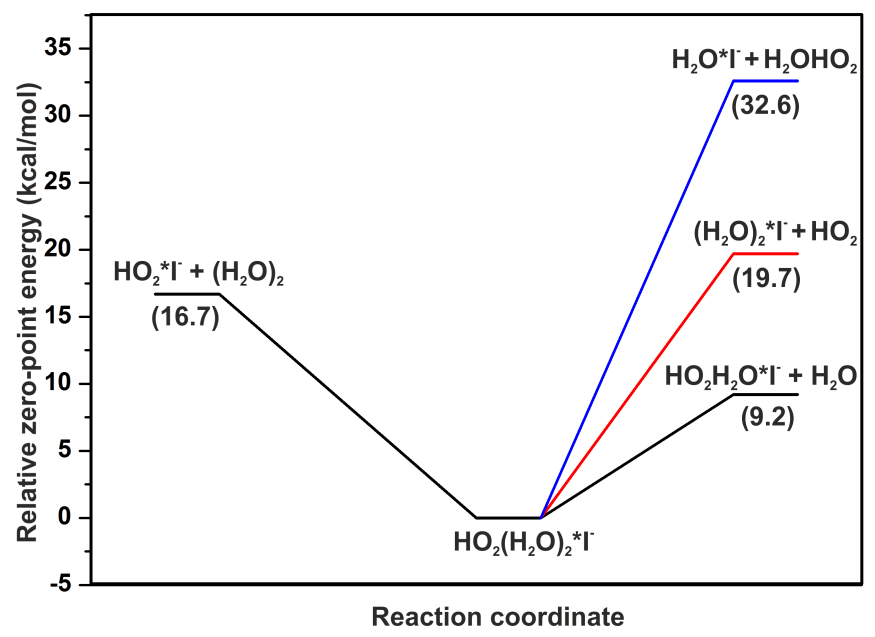

Figure 5: Potential energy surfaces showing the barrier (in zero-point energies) required for possible ligand-exchange reactions resulting in the loss of $\mathrm{HO}_{2}{ }^{*} \mathrm{I}^{-}$and the increase in $\mathrm{H}_{2} \mathrm{O}^{*} \mathrm{I}^{-}$ clusters. The dependence on both monomer (a) and dimer (b) water molecules were tested. Energies were calculated at the PBE/aug-cc-pVTZ-PP level at $298 \mathrm{~K}$.

Water concentrations were varied from RHs below $1 \%$ to $45 \%$. The ligand-exchange reaction to form hydrated iodide clusters from $\mathrm{HO}_{2}{ }^{*} \mathrm{I}^{-}$is highly unfavorable (see (a) in Fig. 5). This means that the $\mathrm{HO}_{2}{ }^{*} \mathrm{I}^{-}$concentrations should not decrease by ligand-exchange reactions at any humidity. The $\mathrm{H}_{2} \mathrm{O}^{*} \mathrm{HO}_{2}$ pathway with the loss of the $\mathrm{I}^{-}$reagent ion is even less favorable, and can therefore be discounted. Increasing the water or water dimer concentration had no significant effect on the $\mathrm{HO}_{2}{ }^{*} \mathrm{I}^{-}$clusters. Therefore, the MESMER simulation does not explain the observed loss in the $\mathrm{HO}_{2}{ }^{*} \mathrm{I}^{-}$signal with an increase in $\mathrm{RH}$. It is likely that there is an $\mathrm{RH}$ region where $\mathrm{HO}_{2}{ }^{*} \mathrm{I}^{-}$signal increases with increasing $\mathrm{RH}$ due to the kinetic effects afforded by a water molecule discussed previously. However, the humidity measurements are always at RHs above this region due to the $\mathrm{N}_{2}$ /water flow for $\mathrm{HO}_{2}$ production.

Further investigation of the experimental data showed that, at $\mathrm{RH}$ above $4 \%$, signals corresponding to $\mathrm{I}^{-}$clustered to water dimers, trimers, and tetramers appeared to increase. 
The detection of water tetramers clustered to $\mathrm{I}^{-}$would point to $\mathrm{I}^{-}$ions clustered to even higher water clusters in the ambient pressure IMR region. Free energies of formation of $\mathrm{H}_{2} \mathrm{O}^{*} \mathrm{I}^{-}$, $\left(\mathrm{H}_{2} \mathrm{O}\right)_{2}{ }^{*} \mathrm{I}^{-},\left(\mathrm{H}_{2} \mathrm{O}\right)_{3} * \mathrm{I}^{-}$and $\left(\mathrm{H}_{2} \mathrm{O}\right)_{4}{ }^{*} \mathrm{I}^{-}$clusters (calculated at the PBE/aug-cc-pVTZ-PP level) by step-wise addition of $\mathrm{H}_{2} \mathrm{O}$ to $\mathrm{I}^{-}$showed that the formation of the higher hydrated $\mathrm{I}^{-}$ ions is favorable (see Table S4 in SI for energies). The high degree of hydration of the $\mathrm{I}^{-}$ ions could make it difficult for it to cluster with the $\mathrm{HO}_{2}$ radical (i.e. decrease the $\mathrm{HO}_{2}{ }^{*} \mathrm{I}^{-}$ formation rate due to steric hindrance), thus reducing the $\mathrm{HO}_{2}{ }^{*} \mathrm{I}^{-}$signal. Another channel for $\mathrm{HO}_{2}$ loss that was investigated was the formation of $\mathrm{H}_{2} \mathrm{O}_{2}$. The peak corresponding to $\mathrm{H}_{2} \mathrm{O}_{2}{ }^{*} \mathrm{I}^{-}$cluster was observed to increase at high RH. As shown in Fig. 6, the $\mathrm{H}_{2} \mathrm{O}_{2}{ }^{*} \mathrm{I}^{-}$signal increases in relation to the decreasing $\mathrm{HO}_{2}{ }^{*} \mathrm{I}^{-}$signal at $\mathrm{RH}$ in the range of $4-45 \%$.

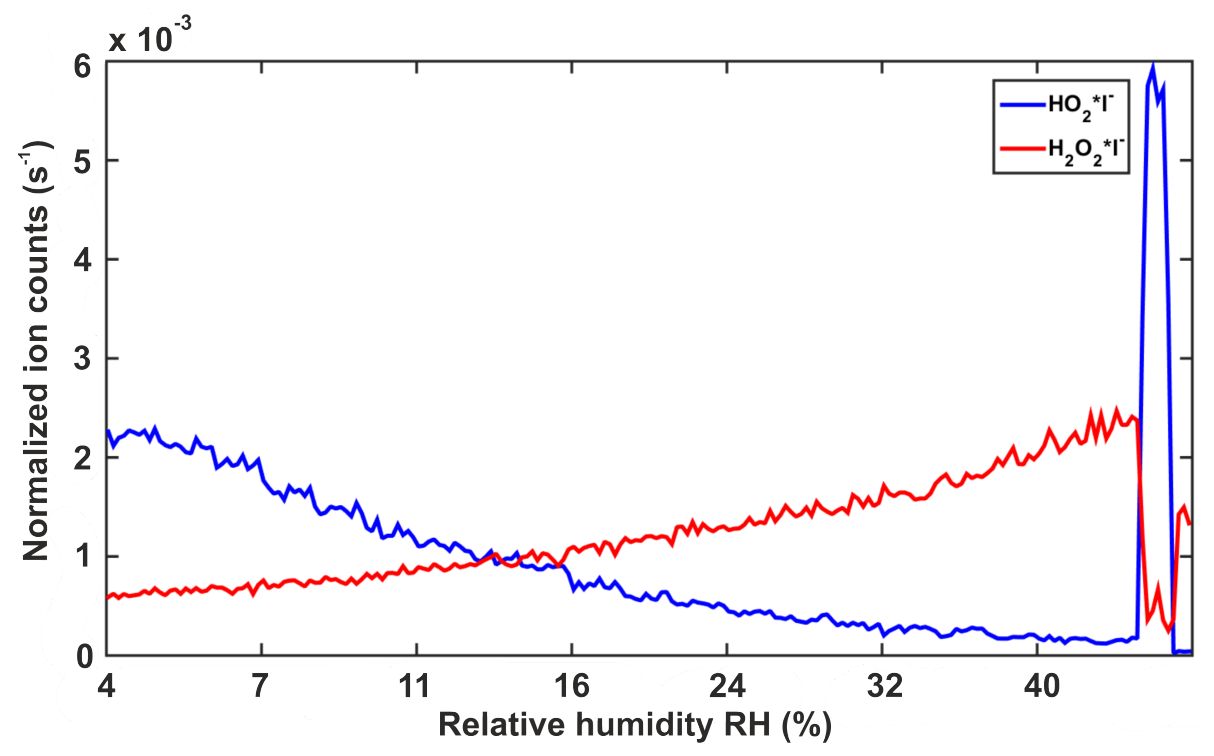

Figure 6: Correlation between $\mathrm{HO}_{2}{ }^{*} \mathrm{I}^{-}$and $\mathrm{H}_{2} \mathrm{O}_{2} * \mathrm{I}^{-}$signals during the humidity dependence measurement. The sudden increase in the $\mathrm{HO}_{2}{ }^{*} \mathrm{I}^{-}$signal and the decrease in the $\mathrm{H}_{2} \mathrm{O}_{2}{ }^{*} \mathrm{I}^{-}$ signal in the latter stage of the measurement process corresponds to the measurement step where the humidity flow was switched off, reducing the water concentration inside the system.

It is important to note that the iodide-CIMS likely detects the $\mathrm{HO}_{2}{ }^{*} \mathrm{I}^{-}$cluster at a higher sensitivity than the $\mathrm{H}_{2} \mathrm{O}_{2}{ }^{*} \mathrm{I}^{-}$cluster. The binding enthalpies of $\mathrm{HO}_{2} * \mathrm{I}^{-}$and $\mathrm{H}_{2} \mathrm{O}_{2} * \mathrm{I}^{-}$(at PBE/aug-cc-pVTZ-PP level) are 21.6 and $18 \mathrm{kcal} / \mathrm{mol}$, respectively (giving them predicted 
sensitivities of 0.40 and $\left.0.03 \mathrm{cps} / \mathrm{ppt}^{14}\right)$. Despite the different sensitivities, a clear correlation between the two molecule signals would indicate a mechanism that converts $\mathrm{HO}_{2}$ to $\mathrm{H}_{2} \mathrm{O}_{2}$ in high RH conditions. Considering the lack of humidity dependence of the $\mathrm{HO}_{2}{ }^{*} \mathrm{Br}^{-}$signal in a bromide-based chemical ionization mass spectrometer reported by Sanchez et al., ${ }^{18}$ iodide might be playing a role in converting $\mathrm{HO}_{2}$ into $\mathrm{H}_{2} \mathrm{O}_{2}$. The favorability of a joint iodide and water catalyzed $\mathrm{HO}_{2}$ recombination reaction was investigated by considering the following reactions:

$$
\begin{gathered}
\mathrm{HO}_{2} * \mathrm{I}^{-}+\mathrm{HO}_{2} \rightarrow \mathrm{H}_{2} \mathrm{O}_{2} * \mathrm{I}^{-}+\mathrm{O}_{2} \\
\mathrm{HO}_{2} * \mathrm{IH}_{2} \mathrm{O}^{-}+\mathrm{HO}_{2} \rightarrow \mathrm{H}_{2} \mathrm{O}_{2} * \mathrm{IH}_{2} \mathrm{O}^{-}+\mathrm{O}_{2} \\
\mathrm{HO}_{2} * \mathrm{I}\left(\mathrm{H}_{2} \mathrm{O}\right)_{2}^{-}+\mathrm{HO}_{2} \rightarrow \mathrm{H}_{2} \mathrm{O}_{2} * \mathrm{I}\left(\mathrm{H}_{2} \mathrm{O}\right)_{2}^{-}+\mathrm{O}_{2}
\end{gathered}
$$

Note: only the reaction energies (i.e. the energy difference between reactants and products) were computed here due to the computational difficulties in treating transition states of radical-radical reactions, especially ones including heavy atoms such as iodide. The existence of an actual barrier between the intermediate cluster and the products was not explored. All three reactions were downhill in enthalpy, at -30.64, -29.74 and -34 kcal/mol, respectively. Considering that the $\mathrm{RH}$ inside the system is $\sim 3-5 \%$ even at zero humidifying flow (the constant photolyzing $\mathrm{N}_{2} / \mathrm{H}_{2} \mathrm{O}$ flow for $\mathrm{HO}_{2}$ production contributes to the $\sim 3-5 \% \mathrm{RH}$ ), the primary reagent ion is most likely $\mathrm{I}^{-}$clustered to one or multiple water molecules. Reactions 7 and 8 are therefore more likely to occur in this system. The above enthalpies would indicate the formation of $\mathrm{H}_{2} \mathrm{O}_{2}{ }^{*} \mathrm{I}^{-}$clusters could be catalyzed by $\mathrm{I}^{-}$and water (i.e. reaction 8 with $\mathrm{I}^{-}$ clustered to two water molecules is more favorable than reaction 7 with $\mathrm{I}^{-}$clustered to one water molecule). However, conclusively proving this issue would require investigation of the actual reaction mechanisms (transition states) in even larger water clusters. As radical-radical mechanisms are notoriously hard to treat accurately, this is beyond the scope of the present study. 


\section{Cyclohexene ozonolysis products}

The detection of the $\mathrm{HO}_{2}$ radical by the iodide-CIMS was followed by the detection of peroxy radical intermediates from cyclohexene ozonolysis and closed-shell products from $\mathrm{RO}_{2}+$ $\mathrm{HO}_{2}$ bimolecular reactions. There are many known bimolecular reactions between $\mathrm{RO}_{2}$ peroxy radicals and $\mathrm{HO}_{2}$. Here, we look at the main pathway leading to the production of hydroperoxides: ${ }^{1,40}$

$\mathrm{RO}_{2}+\mathrm{HO}_{2} \longrightarrow \mathrm{ROOH}+\mathrm{O}_{2}$

The mechanisms for the gas-phase ozone-alkene reaction are well established. ${ }^{41-43}$ It should be noted that there are multiple potential channels. Here, we focus on the vinylhydroperoxide channel (VHP) that has been previously observed to lead to HOMs. Briefly, ozonolysis of cyclohexene forms a primary ozonide (POZ) that instantly decomposes into a Criegee intermediate (CI). The CI isomerizes to form a VHP, which loses an OH-radical, forming a resonance stabilized vinoxy radical radical $\mathrm{C}_{6} \mathrm{H}_{9} \mathrm{O}_{2}$. The carbon centered radical undergoes an $\mathrm{O}_{2}$ addition to form an oxygen-centered peroxy radical $\mathrm{C}_{6} \mathrm{H}_{9} \mathrm{O}_{4}$. The reaction steps are illustrated in Fig. 7. 
Figure 7: Ozonolysis reaction of cyclohexene forming a primary ozonide (POZ) that decomposes into a Criegee intermediate (CI). The CI isomerizes to a vinylhydroperoxide (VHP), followed by the loss of $\mathrm{OH}$, forming a vinoxy radical $\mathrm{C}_{6} \mathrm{H}_{9} \mathrm{O}_{2}$, which adds an $\mathrm{O}_{2}$ molecule to form an oxygen-centered peroxy radical $\mathrm{C}_{6} \mathrm{H}_{9} \mathrm{O}_{4}$.

The oxygen-centered peroxy radical $\mathrm{C}_{6} \mathrm{H}_{9} \mathrm{O}_{4}$ is able to undergo internal hydrogen shift (H-shift) reactions, which is followed by autoxidation to form HOMs. The mechanism to form the HOMs and the structures of these molecules is provided by Rissanen et al. ${ }^{4}$ The detection of peroxy radicals and the closed-shell molecules considered in this study by an iodide-CIMS was investigated by first exploring the molecule- $\mathrm{I}^{-}$cluster binding enthalpies quantum chemically. The optimized peroxy radical $\mathrm{C}_{6} \mathrm{H}_{9} \mathrm{O}_{4}$ geometry is shown in Fig. 8. The optimizations were performed at the PBE/aug-cc-pVTZ-PP level. 


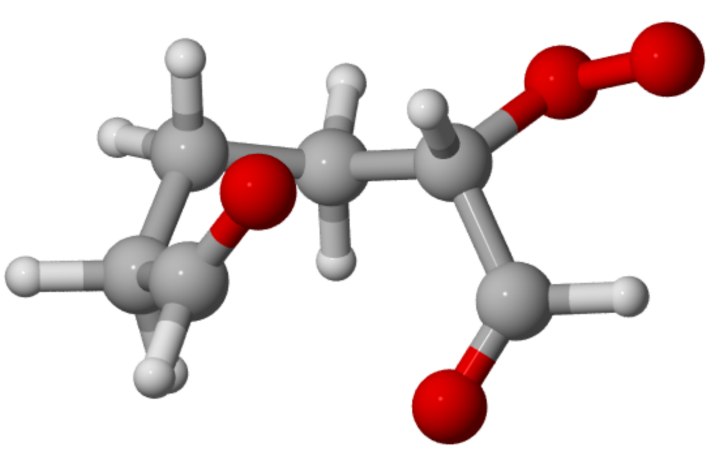

Figure 8: Initial peroxy radical following the ozonolysis of cyclohexene computed at the PBE/aug-cc-pVTZ-PP level. The absence of a hydroxy or a hydroperoxy group means that the molecule is unlikely to cluster with $\mathrm{I}^{-}$. Color coding: Carbon - grey, oxygen - red, hydrogen - white.

The lack of a hydrogen bond donating group makes it improbable that the molecule would cluster with $\mathrm{I}^{-}$. Following the bimolecular reaction with $\mathrm{HO}_{2}$, the closed-shell product $\mathrm{C}_{6} \mathrm{H}_{10} \mathrm{O}_{4}$ should cluster with $\mathrm{I}^{-}$and is subsequently detected by the instrument. The further oxidized radical $\mathrm{C}_{6} \mathrm{H}_{9} \mathrm{O}_{6}$ and the corresponding closed-shell product $\mathrm{C}_{6} \mathrm{H}_{10} \mathrm{O}_{6}$ both have at least one H-bond donating hydroperoxy group which can bind with $\mathrm{I}^{-}$. The optimized free molecule and molecule*I $\mathrm{I}^{-}$complex geometries are shown in Fig. 9. The lowest energy free molecule conformers for the molecules that contain a peroxy acid group were those with the $\mathrm{OOH}$ hydrogen-bonded to the $\mathrm{C}=\mathrm{O}$ oxygen of the acid group. The quantum chemically calculated binding enthalpies of the radical and closed-shell molecules to $\mathrm{I}^{-}$are given in Table 1. 


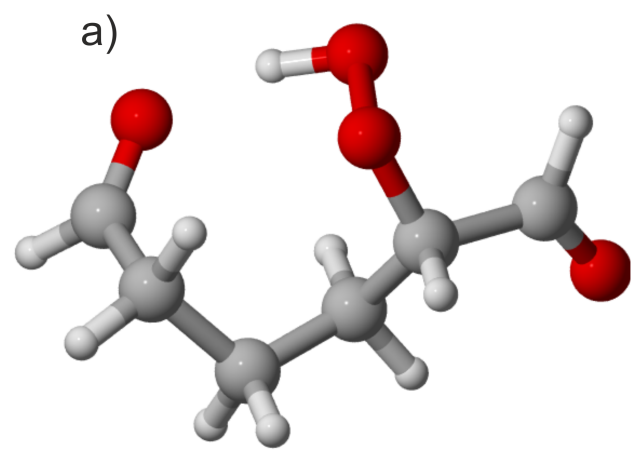

c)
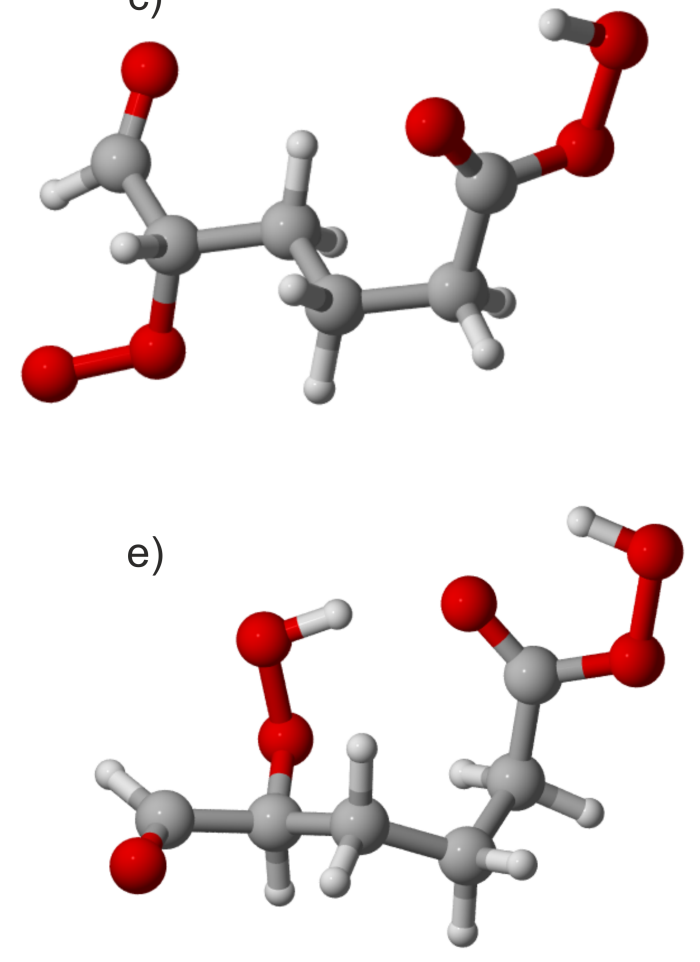

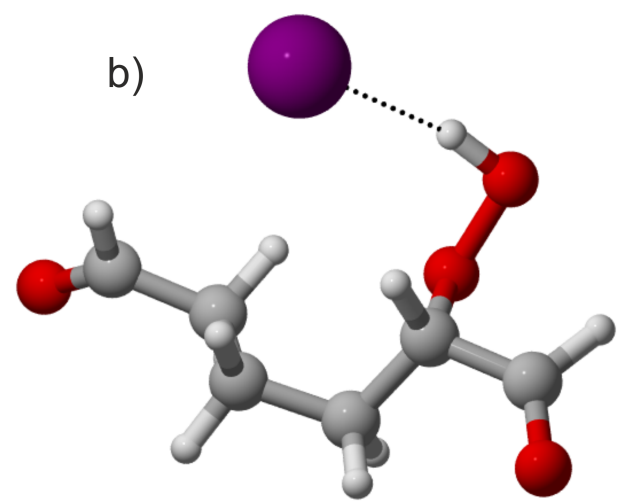

d)
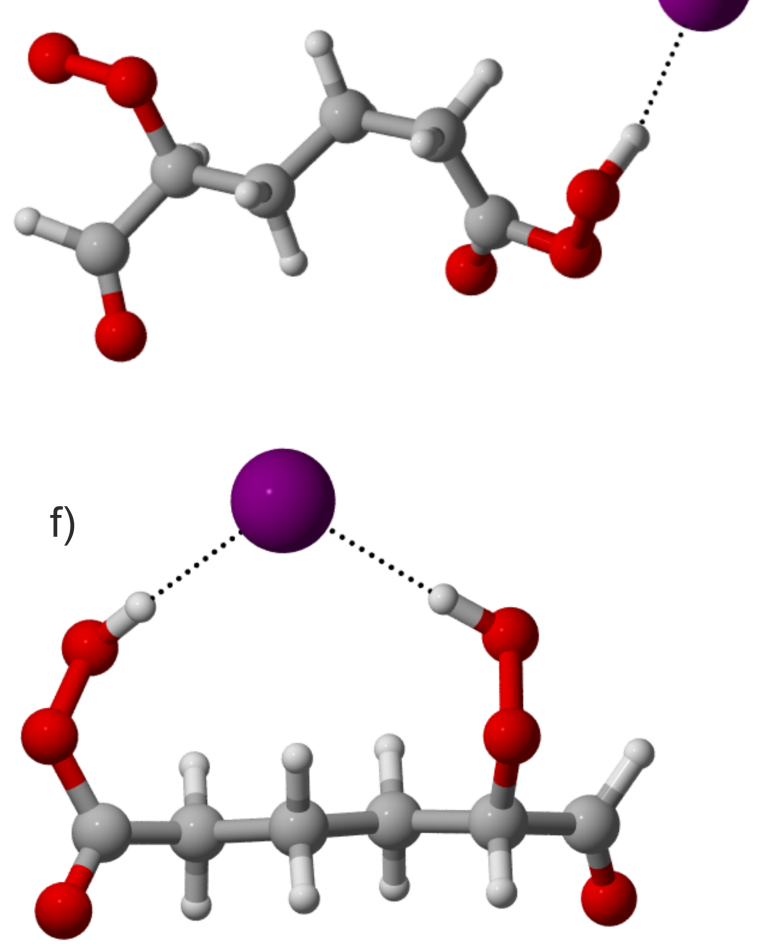

Figure 9: Lowest enthalpy free molecule geometries of the closed-shell product $\mathrm{C}_{6} \mathrm{H}_{10} \mathrm{O}_{4}$, the cyclohexene autoxidation peroxy radical $\mathrm{C}_{6} \mathrm{H}_{9} \mathrm{O}_{6}$, the corresponding closed-shell product $\mathrm{C}_{6} \mathrm{H}_{10} \mathrm{O}_{6}$ (a, c, e, respectively) and their lowest enthalpy clusters with $\mathrm{I}^{-}$(b, d, f, respectively). Geometry optimization was performed at the PBE/aug-cc-pVTZ-PP level. Color coding: Carbon - grey, oxygen - red, hydrogen - white, iodide - purple. 
Table 1: Binding Enthalpies (BE) of Cyclohexene Ozonolysis Products with $\mathrm{I}^{-}$. Calculations were Performed at the PBE/aug-cc-pVTZ-PP Level for the Radical and at the DLPNOCCSD(T)/def2QZVPP//PBE/aug-cc-pVTZ-PP Level for the Closed-Shell Species. Predicted Sensitivities were Calculated from the Model Proposed in Iyer et al. ${ }^{14}$ at the Corresponding Levels of Theory.

\begin{tabular}{|l|l|l|l|}
\hline molecule & DFT BE (kcal/mol) & CCSD $(\mathrm{T})$ corrected BE (kcal/mol) & predicted sensitivity (cps/ppt) \\
\hline $\mathrm{C}_{6} \mathrm{H}_{9} \mathrm{O}_{6}$ & 23.64 & - & $1.74^{a}$ \\
\hline $\mathrm{C}_{6} \mathrm{H}_{10} \mathrm{O}_{4}$ & 22.14 & 22.41 & $0.99^{b}$ \\
\hline $\mathrm{C}_{6} \mathrm{H}_{10} \mathrm{O}_{6}$ & 25.85 & 24.39 & $3.98^{b}$ \\
\hline
\end{tabular}

${ }^{a}$ Predicted sensitivity taken from the model calculated at PBE/aug-cc-pVTZ-PP level and ${ }^{b}$ at DLPNO-CCSD(T)/def2-QZVPP//PBE/aug-cc-pVTZ-PP level.

The stronger binding of the closed-shell $\mathrm{C}_{6} \mathrm{H}_{10} \mathrm{O}_{6}$ product is due to the two hydroperoxy groups contributing to the double hydrogen bond to iodide (see Fig. 9). The calculated binding enthalpies of the radical and closed-shell species are close to the "maximum sensitivity" binding enthalpies discussed in Iyer et al. ${ }^{14}$ and should be detected at similar efficiencies.

\section{Dehydroxylated and deoxygenated peaks in the I-CIMS spectrum}

In addition to the molecule* $\mathrm{I}^{-}$cluster peaks, the cyclohexene ozonolysis experiment produced a number of organic molecular ion peaks in the iodide-CIMS spectrum, which pointed towards iodide ion related chemistry in the IMR region of the mass spectrometer. For the correct identification of the peak compositions, we looked at possible mechanisms that could be involved in producing the observed organic molecular ions. One proposed mechanism is the dehydroxylation of peroxy acids by iodide anion in the presence of water: ${ }^{15,16}$

$$
\mathrm{RC}(\mathrm{O}) \mathrm{OOH}+\mathrm{H}_{2} \mathrm{O} * \mathrm{I}^{-} \rightarrow \mathrm{RC}(\mathrm{O}) \mathrm{O}^{-}+\mathrm{HOI}+\mathrm{H}_{2} \mathrm{O}
$$

To understand the kinetics of the reaction, we considered the smallest peroxy acid, peroxyacetic acid, in our computational study. The calculations were performed at the PBE/aug-cc-pVTZPP level. Fig. 10 illustrates the peroxyacetic acid dehydroxylation reaction. 


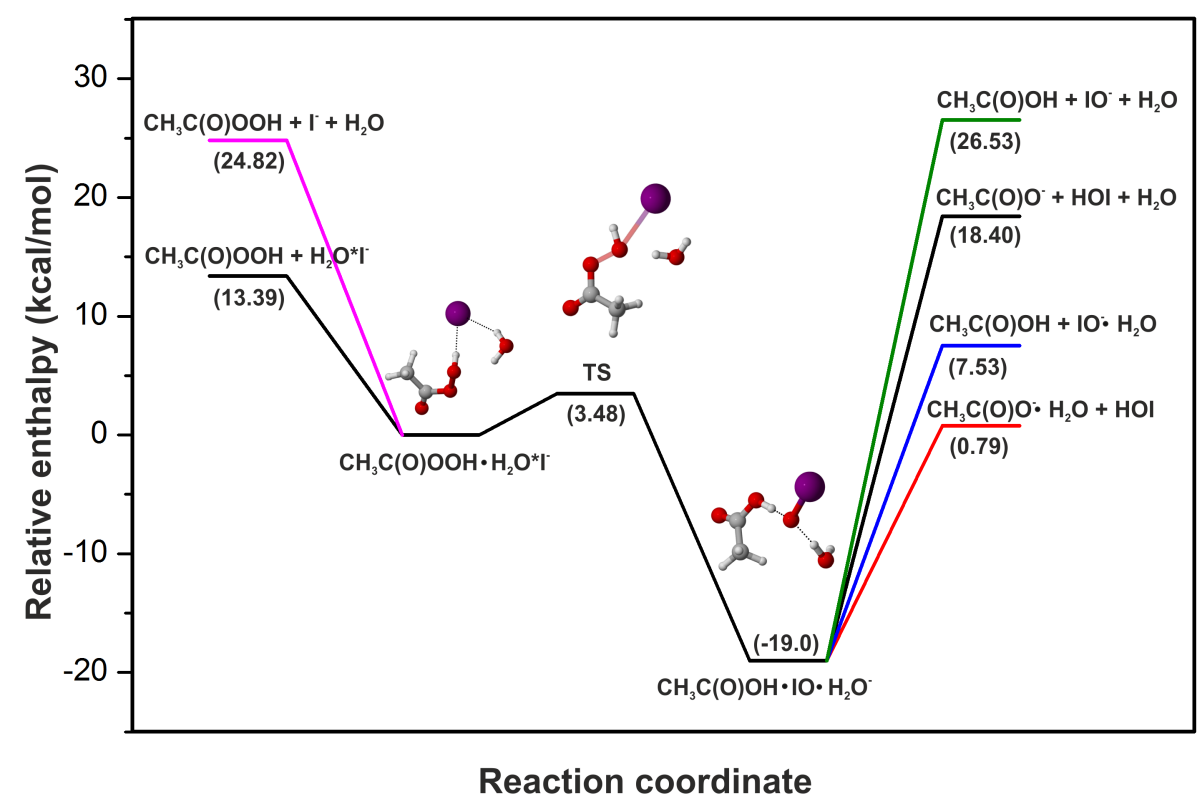

Figure 10: Potential energy surface for the dehydroxylation reaction of peroxyacetic acid with $\mathrm{H}_{2} \mathrm{O}^{*} \mathrm{I}^{-}$. Calculations were performed at the PBE/aug-cc-pVTZ-PP level at $298 \mathrm{~K}$. On the reactant side, the black line denotes the reactant energies with $\mathrm{H}_{2} \mathrm{O}^{*} \mathrm{I}^{-}$as the reagent ion and the pink line with $\mathrm{I}^{-}$and $\mathrm{H}_{2} \mathrm{O}$ as seperate reactants. Color coding: Carbon - grey, oxygen - red, hydrogen - white, iodide - purple.

When considering $\mathrm{I}^{-}$and water as separate reactants in the formation of the $\mathrm{CH}_{3} \mathrm{C}(\mathrm{O}) \mathrm{OOH} \cdot \mathrm{H}_{2} \mathrm{O}^{*} \mathrm{I}^{-}$ complex, the pathway for the formation of the dehydroxylated acetate ion is more favorable. However, it seems more reasonable to assume that peroxyacetic acid would rather encounter $\mathrm{H}_{2} \mathrm{O}^{*} \mathrm{I}^{-}$clusters as they are expected to be formed at high concentrations. This would make the reverse reaction, i.e. back to the parent peroxyacetic acid and $\mathrm{H}_{2} \mathrm{O}^{*} \mathrm{I}^{-}$molecules, more favorable for the molecule-ion complex. However, when considering free energies, which takes into account the higher entropy involved in the formation of the three product species, the dehydroxylation pathway is indeed more favorable (see Fig. 11). 


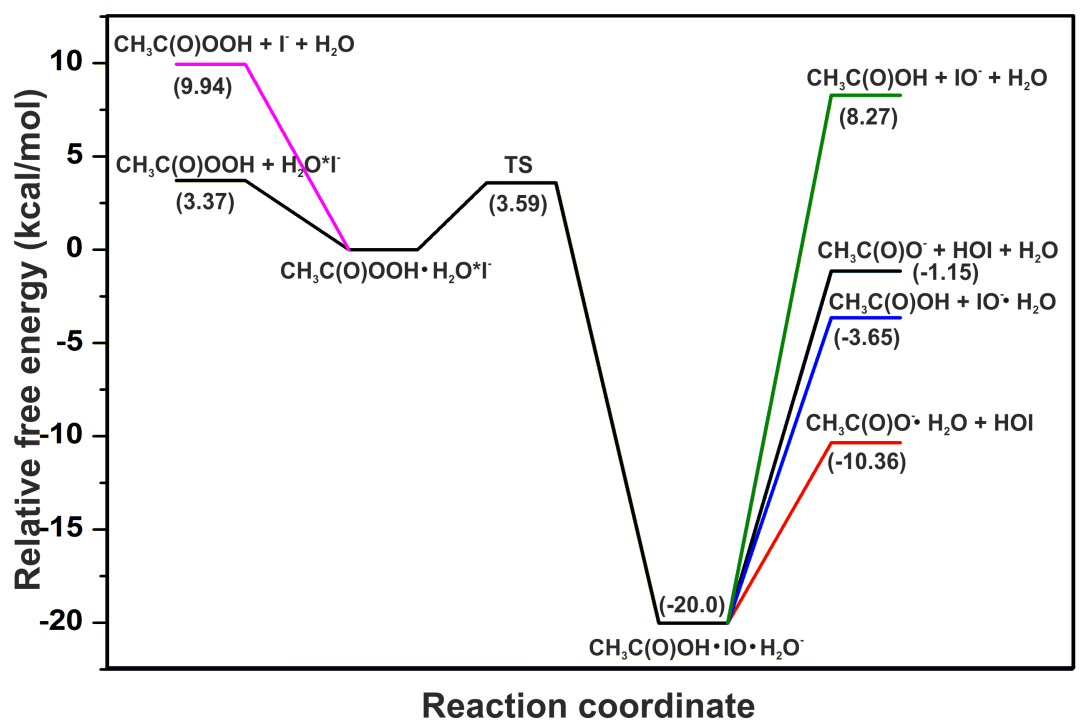

Figure 11: Free energy surface for the dehydroxylation channel. On the reactant side, the black line denotes the reactant energies with $\mathrm{H}_{2} \mathrm{O}^{*} \mathrm{I}^{-}$as the reagent ion and the pink line with $\mathrm{I}^{-}$and $\mathrm{H}_{2} \mathrm{O}$ as seperate reactants. Calculations performed at the PBE/aug-cc-pVTZ-PP level at $298 \mathrm{~K}$.

The most favorable product pathway would appear to be the dehydroxylated carboxylate ion clustered with water + HOI.

In addition to dehydroxylation, a mechanism for the dissociation of an oxygen atom from acyl peroxy radicals by $\mathrm{H}_{2} \mathrm{O}^{*} \mathrm{I}^{-}$has also been reported. ${ }^{15,16}$

$\mathrm{RC}(\mathrm{O}) \mathrm{OO} \cdot+\mathrm{H}_{2} \mathrm{O} \cdot \mathrm{I}^{-} \longrightarrow \mathrm{RC}(\mathrm{O}) \mathrm{O}^{-}+\mathrm{IO} \cdot+\mathrm{H}_{2} \mathrm{O}$

The dissociation pathway of an acyl peroxy radical using the quantum chemically calculated enthalpies is shown in Fig. 12 and the corresponding pathway using free energies is shown in Fig. 13. 


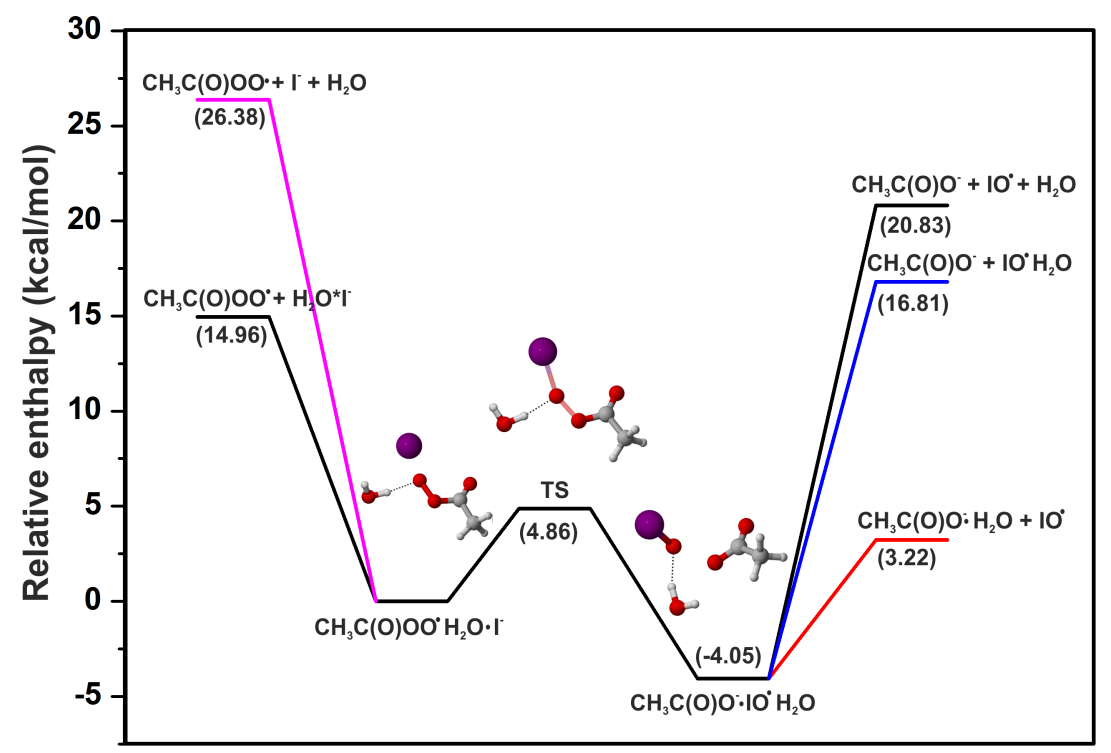

Reaction coordinate

Figure 12: Potential energy surface for the dissociation reaction of $\mathrm{CH}_{3} \mathrm{C}(\mathrm{O}) \mathrm{OO}$ - radical forming a $\mathrm{CH}_{3} \mathrm{C}(\mathrm{O}) \mathrm{O}^{-}$ion. On the reactant side, the black line denotes the reactant energies with $\mathrm{H}_{2} \mathrm{O}^{*} \mathrm{I}^{-}$as the reagent ion and the pink line with $\mathrm{I}^{-}$and $\mathrm{H}_{2} \mathrm{O}$ as seperate reactants. Color coding: Carbon - grey, oxygen - red, hydrogen - white, iodide - purple. Calculations performed at the PBE/aug-cc-pVTZ-PP level at $298 \mathrm{~K}$. 


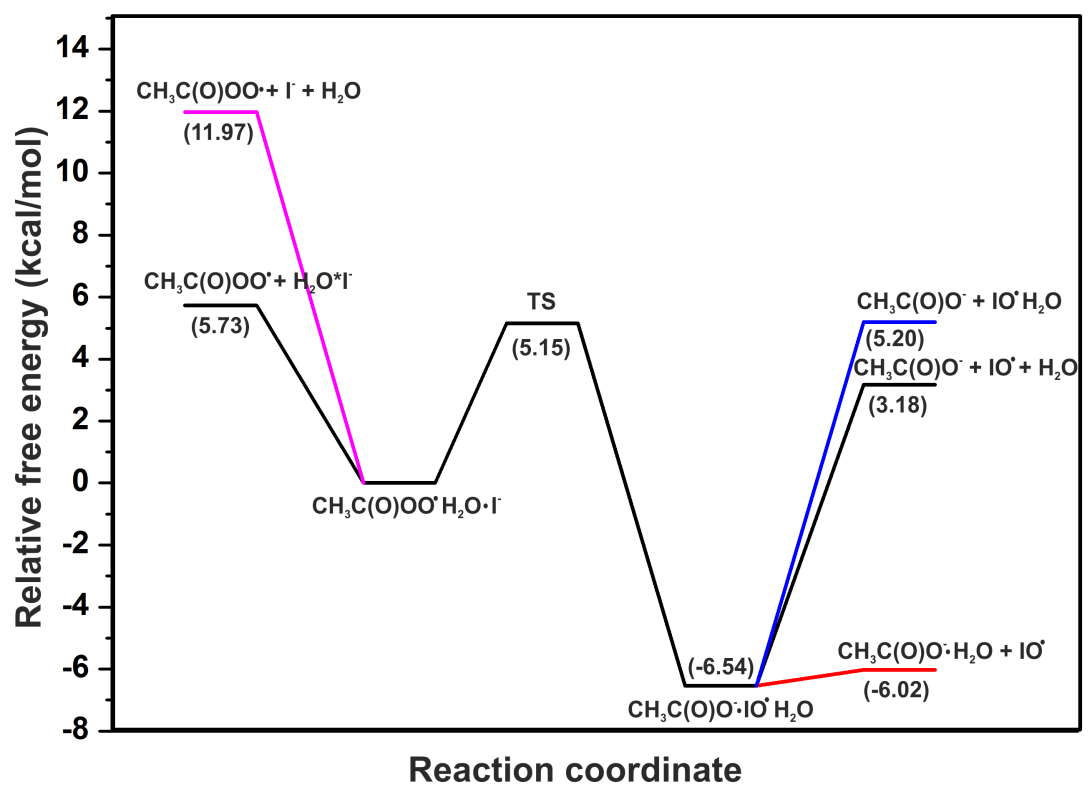

Figure 13: Free energy surface for the dissociation reaction. On the reactant side, the black line denotes the reactant energies with $\mathrm{H}_{2} \mathrm{O}^{*} \mathrm{I}^{-}$as the reagent ion and the pink line with $\mathrm{I}^{-}$ and $\mathrm{H}_{2} \mathrm{O}$ as seperate reactants. Calculations performed at the PBE/aug-cc-pVTZ-PP level at $298 \mathrm{~K}$.

Identifying the organic molecular ions in the iodide-CIMS spectrum as dehydroxylated or deoxygenated products is not straightforward. For example, in the cyclohexene ozonolysis spectrum, the peak corresponding to $\mathrm{C}_{6} \mathrm{H}_{9} \mathrm{O}_{5}^{-}$could be the dehydroxylated product of the closed-shell species $\mathrm{C}_{6} \mathrm{H}_{10} \mathrm{O}_{6}$ or the deoxygenated product of the radical $\mathrm{C}_{6} \mathrm{H}_{9} \mathrm{O}_{6}$. According to calculations carried out by Hyttinen et al., ${ }^{44}$ the $\mathrm{C}_{6} \mathrm{H}_{9} \mathrm{O}_{6}$ isomer with the h-atom on the peroxy acid group (b in Fig. 14) is more energetically favorable (by $10 \mathrm{kcal} / \mathrm{mol}$ ) than the acyl peroxy radical isomer (a in Fig. 14). ${ }^{44}$

a)<smiles>[O]OC(=O)CCCC(C=O)OO</smiles>

b)<smiles>[O]OC(C=O)CCCC(=O)OO</smiles>

Figure 14: Cyclohexene ozonolysis product $\mathrm{C}_{6} \mathrm{H}_{9} \mathrm{O}_{6}$ isomers a) acyl peroxy radical and b) peroxy acid. 
We could then assume that the most likely isomer of $\mathrm{C}_{6} \mathrm{H}_{9} \mathrm{O}_{6}$ that would cluster with $\mathrm{I}^{-}$is isomer $\mathbf{b}$. The organic ion of the radical would then be the dehydroxylated $\mathrm{C}_{6} \mathrm{H}_{8} \mathrm{O}_{5}^{-}$. The deoxygenation mechanism is unlikely as the isomer would more preferably have a peroxy radical group than an acyl peroxy radical group. Since the other ozonolysis products of cyclohexene considered in this study are most likely of the form b in Fig. 14 as well, the organic peaks found in the iodide-CIMS spectra can be assumed to be the product of the dehydroxylation process rather than the deoxygenation process.

\section{Comparison between iodide- and nitrate-CIMS spectra}

Details of the cyclohexene ozonolysis experiment are provided in section S4.3 in the SI. The iodide-CIMS spectrum, including the peaks of the selected cyclohexene ozonolysis products, is shown in Fig. 15. It should be noted that the peaks in the spectrum are not normalized with the reagent ion signals. The variation of cyclohexene ozonolysis radical and $\mathrm{RO}_{2}+\mathrm{HO}_{2}$ reaction product signals in the iodide-CIMS during the measurement sequence is shown in Fig. S5 in the SI. The closed-shell product signals were observed to be higher than those of the radicals, which is reasonable, as the radicals are not generally expected to accumulate in the gas mixture. The radicals would either autoxidize or otherwise react with other $\mathrm{HO}_{2}$ and $\mathrm{RO}_{2}$ compounds in the flow tube. 


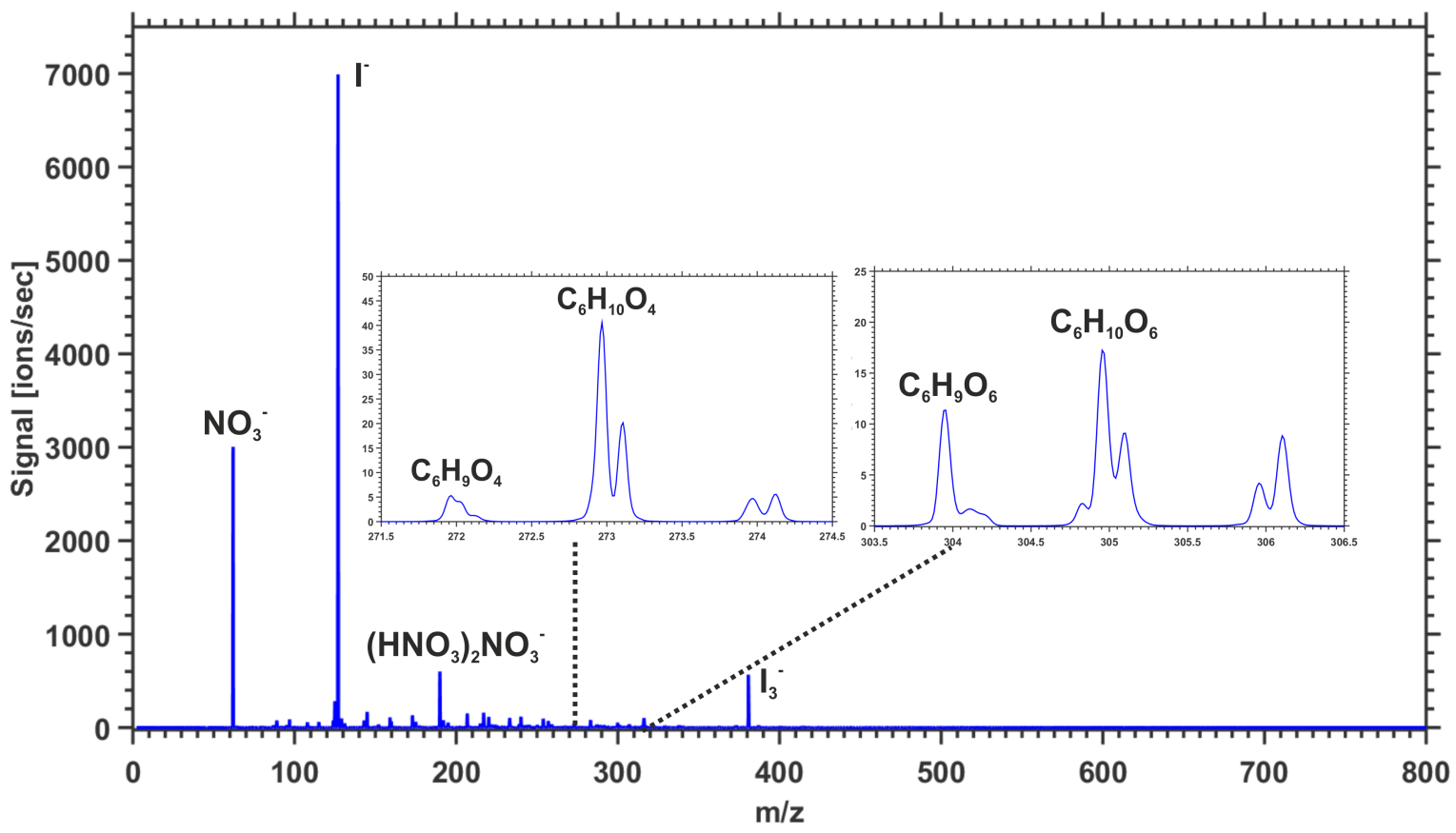

Figure 15: Iodide-CIMS mass spectrum showing selected cyclohexene ozonolysis radical and closed-shell product peaks.

Identical measurement steps were performed with nitrate as the reagent ion. An analysis of the spectra of both these ionization methods can give us a broader understanding of the cyclohexene ozonolysis processes and the influence of $\mathrm{HO}_{2}$ on them. In addition, finding the compositions that are detected exclusively by one of the two methods would help to understand the limits of these techniques.

The nitrate-CIMS spectrum with the cyclohexene ozonolysis and subsequent autoxidation intermediates and products is shown in Fig. 16. By inspection, it is clear that the nitrate spectrum is much cleaner than the iodide spectrum. The high selectivity of nitrate ionization is a clear advantage over iodide when studying highly-oxidized compounds that are known to cluster strongly to nitrate. However, compounds with less than 5 oxygen atoms and lacking in hydroxy/hydroperoxy functional groups are generally not detected by this technique. The variation of cyclohexene ozonolysis intermediate and product signals in the nitrate-CIMS 
during the measurement sequence is shown in Fig. S5 in the SI. The mass defect plot shown in Fig. 17 compares the monomers detected by iodide and nitrate CIMS. Each addition of hydrogen shifts the mass defect of the compound to more positive (MD of $\mathrm{H}$ is +0.008 ), while the addition of oxygen shifts it to more negative (MD of $\mathrm{O}$ is -0.005 ) mass defects.

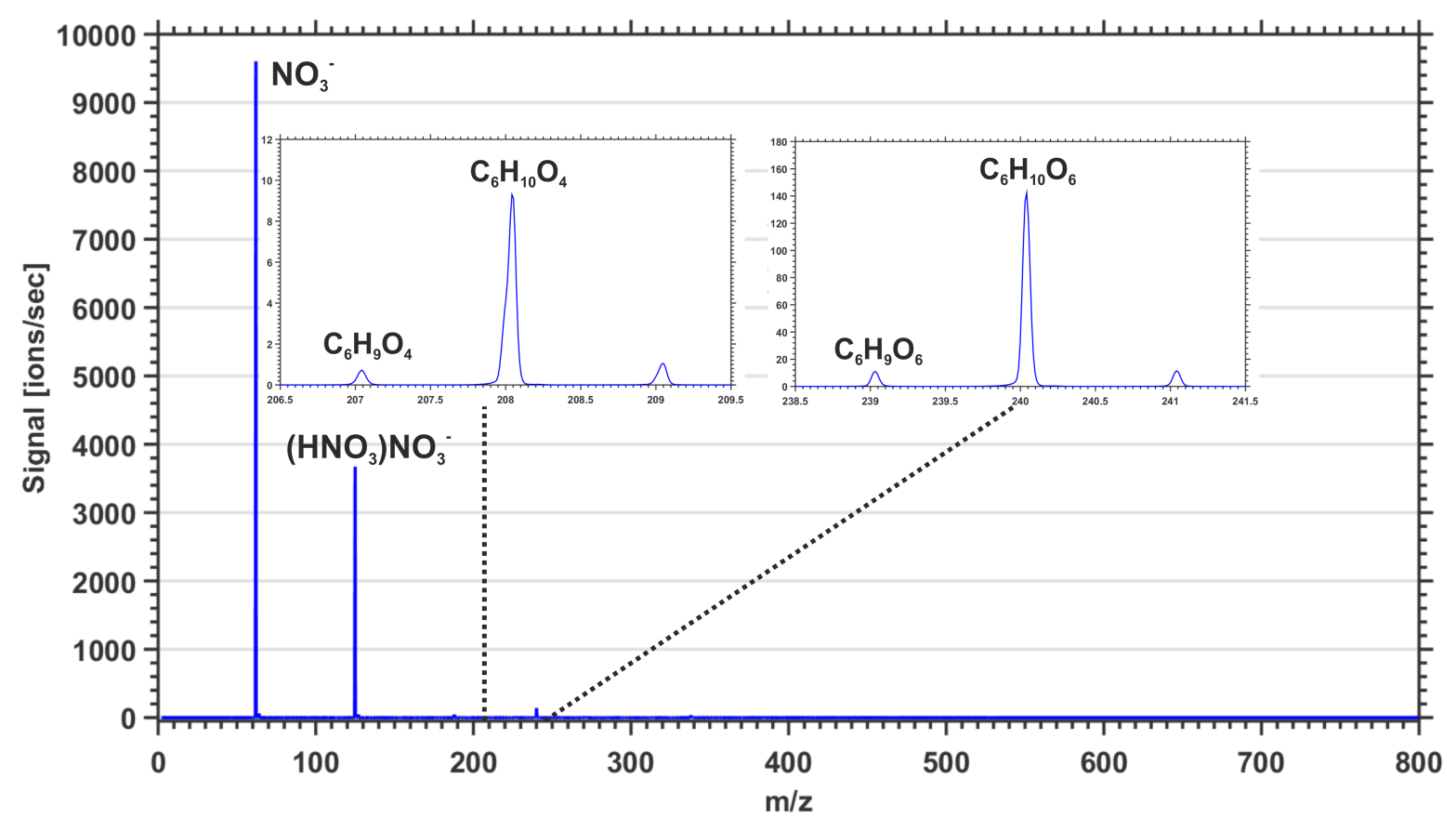

Figure 16: Nitrate-CIMS mass spectrum showing the selected cyclohexene ozonolysis radical product and $\mathrm{RO}_{2}+\mathrm{HO}_{2}$ reaction closed-shell product peaks. 


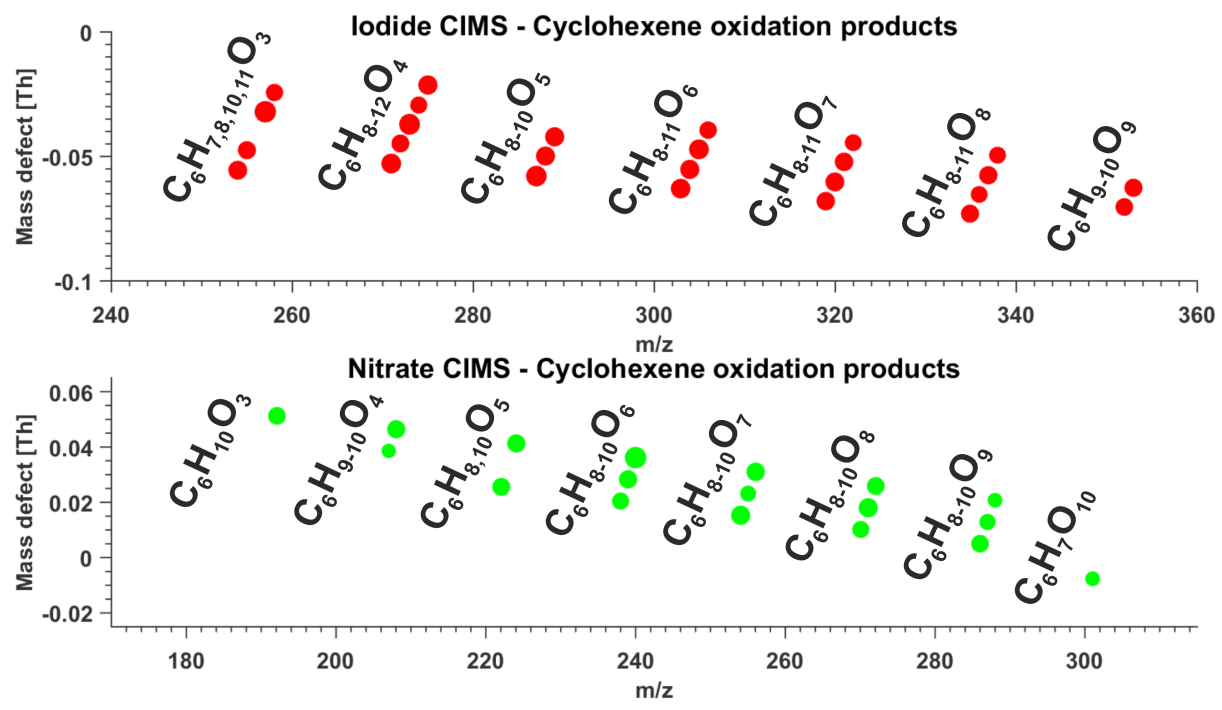

Figure 17: Mass defect plot. Comparison of the peak composition detected by the two ionization methods. Red circles are iodide clustered compounds and green circles represent nitrate clustered compounds. The "columns" represent an addition of oxygen atom, while the "rows" represent the addition of hydrogen atom. Sizes of the circles correspond to the intensity of the signal.

It is clear that iodide-CIMS can detect the lower-oxidized molecules better than nitrate $\mathrm{C}_{6} \mathrm{H}_{7,8,10,11} \mathrm{O}_{3}$ molecules, for example, were detected by iodide, while nitrate was only able to detect $\mathrm{C}_{6} \mathrm{H}_{10} \mathrm{O}_{3}$. Even with regards to the higher oxidized molecules, iodide was able to detect more compounds than nitrate. The only exception here is the $\mathrm{C}_{6} \mathrm{H}_{7} \mathrm{O}_{10}$ molecule that was detected by nitrate but not by iodide. In addition to the molecule- ${ }^{-}$clusters detected by the iodide-CIMS, the carboxylate ions formed due to the dehydroxylation mechanism discussed earlier produced additional peaks in the iodide spectrum.

\section{Dimers}

An investigation into the elemental compositions in the range of $\mathrm{C}_{10-12} \mathrm{H}_{16-18} \mathrm{O}_{3-14}$ in the iodide spectrum revealed a number of cyclohexene products that we believe to be covalently bound dimers. A complete list of molecule- $\mathrm{I}^{-}$clusters with peaks corresponding to the above compositions is provided in Table S3 in the SI. Gas-phase dimer forming mechanisms from 
alkene ozonolysis intermediates and products are not completely understood yet. Here, we look at one mechanism wherein peroxy radicals react (possibly via a complex or indirect mechanism) to form closed-shell peroxide dimers.

$$
\mathrm{RO}_{2}+\mathrm{RO}_{2} \rightarrow \mathrm{ROOR}+\mathrm{O}_{2}
$$

Dimers formed from the peroxy radicals $\mathrm{C}_{6} \mathrm{H}_{9} \mathrm{O}_{4}, \mathrm{C}_{6} \mathrm{H}_{9} \mathrm{O}_{6}$, and $\mathrm{C}_{6} \mathrm{H}_{9} \mathrm{O}_{8}$ were considered in this study. The list of possible dimers is shown in Table 2. The presence of these dimer peaks were investigated in both the iodide and nitrate CIMS spectra. The peak corresponding to the dimer $\mathrm{C}_{12} \mathrm{H}_{18} \mathrm{O}_{14}$ was not visible in either of the spectra. The remaining dimers listed in Table 2 were detected. The changes in the detected dimer signals in the iodide and nitrate-CIMS during the measurement process is shown in Fig. S6 in the SI.

Table 2: Set of Possible Dimers Following Reaction 10 Between the Considered Cyclohexene Ozonolysis Derived $\mathrm{RO}_{2}$ Radicals.

\begin{tabular}{|l|l|l|l|}
\hline & $\mathrm{C}_{6} \mathrm{H}_{9} \mathrm{O}_{4}$ & $\mathrm{C}_{6} \mathrm{H}_{9} \mathrm{O}_{6}$ & $\mathrm{C}_{6} \mathrm{H}_{9} \mathrm{O}_{8}$ \\
\hline $\mathrm{C}_{6} \mathrm{H}_{9} \mathrm{O}_{4}$ & $\mathrm{C}_{12} \mathrm{H}_{18} \mathrm{O}_{6}$ & $\mathrm{C}_{12} \mathrm{H}_{18} \mathrm{O}_{8}$ & $\mathrm{C}_{12} \mathrm{H}_{18} \mathrm{O}_{10}$ \\
\hline $\mathrm{C}_{6} \mathrm{H}_{9} \mathrm{O}_{6}$ & - & $\mathrm{C}_{12} \mathrm{H}_{18} \mathrm{O}_{10}$ & $\mathrm{C}_{12} \mathrm{H}_{18} \mathrm{O}_{12}$ \\
\hline $\mathrm{C}_{6} \mathrm{H}_{9} \mathrm{O}_{8}$ & - & - & $\mathrm{C}_{12} \mathrm{H}_{18} \mathrm{O}_{14}$ \\
\hline
\end{tabular}

The dimer $\mathrm{C}_{12} \mathrm{H}_{18} \mathrm{O}_{6}$ formed by the reaction between two $\mathrm{C}_{6} \mathrm{H}_{9} \mathrm{O}_{4}$ peroxy radicals in their keto/aldehyde forms should not have a hydrogen-bond donating functional group (see Fig. 8), and should therefore not be detected by either iodide or nitrate CIMS. The fact that the $\mathrm{C}_{12} \mathrm{H}_{18} \mathrm{O}_{6}$ dimer peak is detected by both methods suggests, for example, a keto-enol tautomerism reaction forming $\mathrm{OH}$ groups is occuring or that the mechanism forming the dimers, and thus also the structure of the dimers, is not a simple $\mathrm{RO}_{2}$ recombination. The reason for the detection of the remaining dimers in Table 2 is more straightforward as they should all retain at least one hydroperoxy group after the postulated dimer forming reaction, allowing them to cluster with $\mathrm{I}^{-}$and $\mathrm{NO}_{3}^{-}$. 
The previously described dehydroxylation reaction of peroxy acids by $\mathrm{H}_{2} \mathrm{O}^{*} \mathrm{I}^{-}$can be used to probe the structure and composition of the formed dimers. Since dehydroxylation is only applicable for molecules with a peroxy acid group, $\mathrm{C}_{12} \mathrm{H}_{18} \mathrm{O}_{6}$, which is missing a peroxy acid group, should not dehydroxylate, while the remaining dimers should. An investigation of the dehydroxylated dimer peaks showed that this was indeed the case. The dehydroxylated form of the monomer radical $\mathrm{C}_{6} \mathrm{H}_{9} \mathrm{O}_{4}$ was absent from the iodide-spectra as well. The possible dehydroxylated dimers are shown in Table 3. The dehydroxylated ion $\mathrm{C}_{12} \mathrm{H}_{17} \mathrm{O}_{5}^{-}$peak was absent in the spectrum, as expected. The iodide-CIMS spectrum with the dehydroxylated dimer peaks highlighted is shown in Fig. 18. The variation of the rest of the dehydroxylated dimers in Table 3 during the measurement process is shown in Fig. S6 in the SI.

Table 3: Possible Dehydroxylated Dimer Peaks.

\begin{tabular}{|l|l|l|l|}
\hline & $\mathrm{C}_{6} \mathrm{H}_{9} \mathrm{O}_{4}$ & $\mathrm{C}_{6} \mathrm{H}_{9} \mathrm{O}_{6}$ & $\mathrm{C}_{6} \mathrm{H}_{9} \mathrm{O}_{8}$ \\
\hline $\mathrm{C}_{6} \mathrm{H}_{9} \mathrm{O}_{4}$ & $\mathrm{C}_{12} \mathrm{H}_{17} \mathrm{O}_{5}$ & $\mathrm{C}_{12} \mathrm{H}_{17} \mathrm{O}_{7}$ & $\mathrm{C}_{12} \mathrm{H}_{17} \mathrm{O}_{9}$ \\
\hline $\mathrm{C}_{6} \mathrm{H}_{9} \mathrm{O}_{6}$ & - & $\mathrm{C}_{12} \mathrm{H}_{17} \mathrm{O}_{9}$ & $\mathrm{C}_{12} \mathrm{H}_{17} \mathrm{O}_{11}$ \\
\hline $\mathrm{C}_{6} \mathrm{H}_{9} \mathrm{O}_{8}$ & - & - & $\mathrm{C}_{12} \mathrm{H}_{17} \mathrm{O}_{13}$ \\
\hline
\end{tabular}




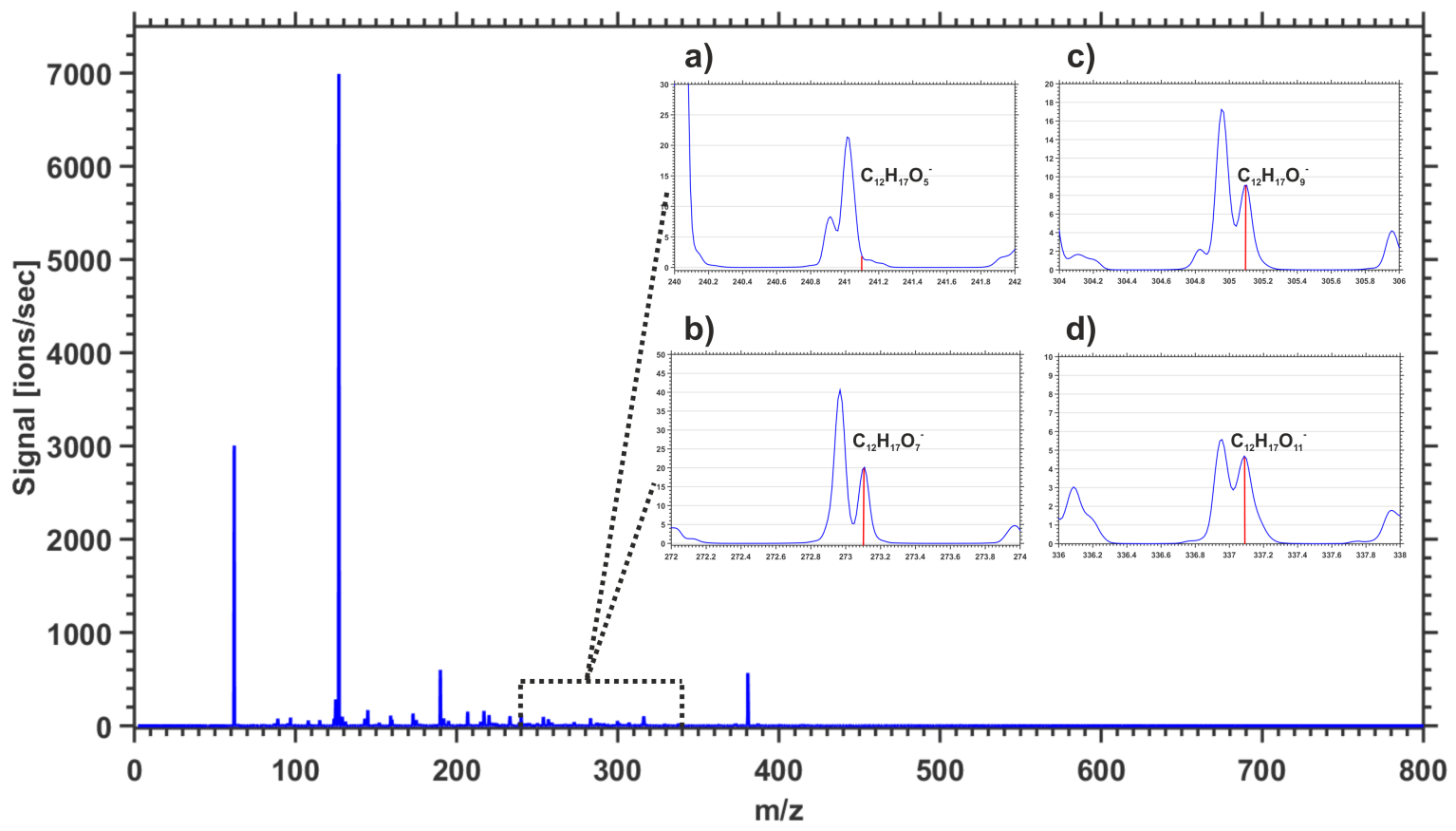

Figure 18: Iodide-CIMS spectrum with the dehydroxylated dimer peaks. [a] shows the absence of the $\mathrm{C}_{12} \mathrm{H}_{17} \mathrm{O}_{5}^{-}$peak $(\mathrm{m} / \mathrm{z} 241.1081)$. The remaining dehydroxylated dimer peaks [b-d] were detected.

\section{Conclusions}

The $\mathrm{HO}_{2}$ radical plays a significant role in atmospheric photochemistry. It is also important in the termination of autoxidation processes of VOCs, a known mechanism for producing HOMs, by reacting with acyl and other peroxy radicals to form closed-shell products. In this work, the direct detection of the $\mathrm{HO}_{2}$ radical by an iodide-CIMS was demonstrated. The experimental work was corroborated by quantum chemically calculated $\mathrm{HO}_{2}{ }^{*} \mathrm{I}^{-}$cluster binding enthalpy. The strong binding of the $\mathrm{HO}_{2}$ radical to $\mathrm{I}^{-}(21.6 \mathrm{kcal} / \mathrm{mol})$ translates to lower fragmentation rates inside the mass spectrometer. However, the $\mathrm{HO}_{2}{ }^{*} \mathrm{I}^{-}$signals showed a strong negative dependence on humidity. RRKM calculations using MESMER pointed to water having a positive effect on the formation of $\mathrm{HO}_{2}{ }^{*} \mathrm{I}^{-}$clusters, revealing faster formation rate of $\mathrm{HO}_{2}{ }^{*} \mathrm{I}^{-}$clusters with $\mathrm{H}_{2} \mathrm{O}^{*} \mathrm{I}^{-}$as the reagent ion compared to the 
un-hydrated $\mathrm{I}^{-}$ion. This is due to the additional vibrational modes of freedom offered by the water molecule, as well as the sacrificial cooling effect from the evaporating water molecule, which both act to stabilize the $\mathrm{HO}_{2}{ }^{*} \mathrm{I}^{-}$cluster. The rise in the $\mathrm{H}_{2} \mathrm{O}_{2}{ }^{*} \mathrm{I}^{-}$signal corresponding with the decrease in the $\mathrm{HO}_{2}{ }^{*} \mathrm{I}^{-}$signal at $\mathrm{RH} \sim 4-45 \%$ might indicate iodide and water catalyzed $\mathrm{HO}_{2}$ recombination reaction that converts the $\mathrm{HO}_{2}$ radical to $\mathrm{H}_{2} \mathrm{O}_{2}$ at high $\mathrm{RH}$. Additionally, the presence of peaks corresponding to $\mathrm{I}^{-}$clustered to up to 4 water molecules at RH higher than $\sim 4 \%$ in the iodide-CIMS spectra would suggest a high degree of hydration of the reagent ion inside the IMR in high RH conditions. Therefore, the likely reason for the loss of $\mathrm{HO}_{2}{ }^{*} \mathrm{I}^{-}$signal at high humidities is the direct steric effect on the ability of the $\mathrm{HO}_{2}$ radical to efficiently cluster with the hydrated $\mathrm{I}^{-}$ion.

The sequence of oxidation reactions advancing by peroxy radical $\mathrm{H}$-shift $+\mathrm{O}_{2}$ addition to form HOM species with O:C ratio of up to 1.5 has been reported previously by Rissanen et al. ${ }^{4}$ Here, we demonstrate the detectability of these compounds by the iodide-CIMS. A comparison with the nirate-CIMS spectra revealed that the highly oxygenated monomer compounds are detected by both methods. However, iodide-CIMS picks up the low-oxidized monomers (O:C ratio 0.5 to 1 ) better than nitrate. Additionally, the $\mathrm{RO}_{2}+\mathrm{HO}_{2}$ bimolecular reaction closed-shell products investigated here are detected well by both methods. Peaks corresponding to dimer compositions studied here were similarly equally well detected by both iodide and nitrate-CIMS. Dehydroxylation of peroxy acids by $\mathrm{H}_{2} \mathrm{O}^{*} \mathrm{I}^{-}$has been reported previously. Here, the mechanism was computationally investigated and confirmed. The dehydroxylated organic peaks in the iodide-CIMS spectra can be used to differentiate compounds with and without peroxy acid groups. This could help to identify the structures of the compositions detected by an iodide-CIMS.

We have shown, both computationally and experimentally, that iodide-CIMS is an important technique for the detection of atmospherically relevant compounds. In addition to 
the direct detection of the $\mathrm{HO}_{2}$ radical and the capability to detect compounds with a wide range of $\mathrm{O}: \mathrm{C}$ ratios, including dimers, the large negative mass defect of iodide makes for easier identification of iodide-clustered peaks in the iodide-CIMS spectra. Furthermore, the dehydroxylation of peroxy acids further helps in elucidating the structures corresponding to the detected elemental compositions.

\section{Supporting information}

The Supporting Information is available free of charge via the Internet at http://pubs.acs.org/ Details about the laboratory experiments, calibration plot for the $\mathrm{HO}_{2}$ radical, MESMER simulations, absolute energetics and the Cartesian coordinates of all structures studied.

\section{Acknowledgements}

We thank the Academy of Finland $(266388,299574)$ for the funding. We thank the tofTools team for providing tools for mass spectrometry analysis. Finally, we thank the CSC IT Center for Science in Espoo, Finland for computing resources.

\section{References}

(1) Hasson, A. S.; Tyndall, G. S.; Orlando, J. J.; Singh, S.; Hernandez, S. Q.; Cambell, S.; and Ibarra, Y. Branching Ratios For the Reaction of Selected Carbonyl-Containing Peroxy Radicals With Hydroperoxy Radicals. J. Phys. Chem. A 2012, 116, 6264-6281.

(2) Mentel, T. F.; Springer, M.; Ehn, M.; Kleist, E.; Pullinen, I.; Kurtén, T.; Rissanen, M.; Wahner, A.; and Wildt, J. Formation of Highly Oxidized Multifunctional Compounds: Autoxidation of Peroxy Radicals Formed in the Ozonolysis of Alkenes - Deduced from Structure-Product Relationships. Atmos. Chem. Phys. 2015, 15, 6745-6765. 
(3) Crounse, J. D.; Nielsen, L. B.; Jørgensen, S.; Kjaergaard, H. G.; and Wennberg, P. O. Autoxidation of Organic Compounds in the Atmosphere. J. Phys. Chem. Lett. 2013, 4, 3513-3520.

(4) Rissanen, M. P.; Kurtén, T.; Sipilä, M.; Thornton, J. A.; Kangasluoma, J.; Sarnela, N.; Junninen, H.; Jørgensen, S.; Schallhart, S.; Kajos, M. K.; et al. The Formation of Highly Oxidized Multifunctional Products in the Ozonolysis of Cyclohexene. J. Am. Chem. Soc. 2014, 136, 15596-15606.

(5) Berndt, T.; Richters, S.; Kaethner, R.; Voigtländer, J.; Stratmann, F.; Sipilä, M.; Kulmala, M.; and Herrmann, H. Gas-Phase Ozonolysis of Cycloalkenes: Formation of Highly Oxidized $\mathrm{RO}_{2}$ Radicals and Their Reactions With $\mathrm{NO}, \mathrm{NO}_{2}, \mathrm{SO}_{2}$, and Other $\mathrm{RO}_{2}$ Radicals. J. Phys. Chem. A 2015, 41, 10336-10348.

(6) Ehn, M.; Thornton, J. A.; Kleist, E.; Sipilä, M.; Junninen, H.; Pullinen, I.; Springer, M.; Rubach, F.; Tillmann, R.; Lee, B.; et al. A Large Source of Low-Volatility Secondary Organic Aerosol. Nature 2014, 506, 476-479.

(7) Bianchi, F.; Tröstl, J.; Junninen, H.; Frege, C.; Henne, S.; Hoyle, C. R.; Molteni, U.; Herrmann, E.; Adamov, A.; Bukowiecki, N.; et al. New Particle Formation in the Free Troposphere: A Question of Chemistry and Timing. Science 2016, 352, 1109-1112.

(8) Ortega, I. K.; Donahue, N. M.; Kurtén, T.; Kulmala, M.; Focsa, C.; and Vehkamäki, H. Can Highly Oxidized Organics Contribute to Atmospheric New Particle Formation? J. Phys. Chem. A 2016, 120, 1452-1458.

(9) Ehn, M.; Kleist, E.; Junninen, H.; Petäjä, T.; Lönn, G.; Schobesberger, S.; Maso, M. D.; Trimborn, A.; Kulmala, M.; Worsnop, D. R.; et al. Gas Phase Formation of Extremely Oxidized Pinene Reaction Products in Chamber and Ambient Air. Atmos. Chem. Phys. 2012, 12, 5113-5127. 
(10) Krechmer, J. E.; Coggon, M. M.; Massoli, P.; Nguyen, T. B.; Crounse, J. D.; Hu, W.; Day, D. A.; Tyndall, G. S.; Henze, D. K.; Rivera-Rios, J. C.; et al. Formation of Low Volatility Organic Compounds and Secondary Organic Aerosol from Isoprene Hydroxyhydroperoxide Low-NO Oxidation. Environ. Sci. Technol. 2015, 49, 1033010339.

(11) Hyttinen, N.; Kupiainen-Määttä, O.; Rissanen M. P.; Muuronen, M.; Ehn, M.; and Kurtén, T. Modeling the Charging of Highly Oxidized Cyclohexene Ozonolysis Products Using Nitrate-Based Chemical Ionization. J. Phys. Chem. 2015, 119, 6339-6345.

(12) Breton, M. L.; McGillen, M. R.; Muller, J. B. A.; Bacak, A.; Shallcross, D. E.; Xiao, P.; Huey, L. G.; Tanner, D.; Coe, H.; and Percival, C. J. Airborne Observations of Formic Acid Using a Chemical Ionization Mass Spectrometer. Atmos. Meas. Tech. 2012, 5, 3029-3039.

(13) Lee, B. H.; Lopez-Hilfiker, F. D.; Mohr, C.; Kurtén, T.; Worsnop, D. R.; and Thornton, J. A. An Iodide-Adduct High-Resolution Time-of-Flight Chemical-Ionization Mass Spectrometer: Application to Atmospheric Inorganic and Organic Compounds. Environ. Sci. Technol. 2014, 48, 6309-6317.

(14) Iyer, S.; Lopez-Hilfiker, F.; Lee, B. H.; Thornton, J. P.; and Kurtén, T. Modeling the Detection of Organic and Inorganic Compounds Using Iodide-Based Chemical Ionization. J. Phys. Chem. A 2016, 120, 576-587.

(15) Mielke, L. H. and Osthoff, H. D. On Quantitative Measurements of Peroxycarboxylic Nitric Anhydride Mixing Ratios by Thermal Dissociation Chemical Ionization Mass Spectrometry. International Journal of Mass Spectrometry 2012, 310, 1-9.

(16) Furgeson, A.; Mielke, L. H.; Paul, D.; and Osthoff, H. D. A Photochemical Source of Peroxypropionic and Peroxyisobutanoic Nitric Anhydride. Atmos. Environ. 2011, 45, $5025-5032$. 
(17) Veres, P. R.; Roberts, J. M.; Wild, R. J.; Edwards, P. M.; Brown, S. S.; Bates, T. S.; Quinn, P. K.; Johnson, J. E.; Zamore, R. J.; and de Gouw, J. Peroxynitric Acid $\left(\mathrm{HO}_{2} \mathrm{NO}_{2}\right)$ Measurements During the UBWOS 2013 and 2014 Studies Using Iodide Ion Chemical Ionization Mass Spectrometry. Atmos. Chem. Phys. 2015, 15, 8101-8114.

(18) Sanchez, J.; Tanner, D. J.; Chen, D.; Huey, L. G.; and Ng, N. L. A New Technique for the Direct Detection of $\mathrm{HO}_{2}$ Radicals Using Bromide Chemical Ionization Mass Spectrometry (Br-CIMS): Initial Characterization. Atmos. Chem. Phys. 2016, 9, 3851-3861.

(19) Junninen, H.; Ehn, M.; Petäjä, T.; Luosujärvi, L.; Kotiaho, T.; Kostiainen, R.; Rohner, U.; Gonin, M.; Fuhrer, K.; Kulmala, M.; et al. A High-Resolution Mass Spectrometer to Measure Atmospheric Ion Composition. Atmos. Meas. Tech. 2010, 3, 1039-1053.

(20) Kurtén, T.; Petäjä, T.; Smith, J.; Ortega, I. K.; Sipilä, M.; Junninen, H.; Ehn, M.; Vehkamäki, H.; Mauldin, L.; Worsnop, D. R.; et al. The Effect of $\mathrm{H}_{2} \mathrm{SO}_{4}$-Amine Clustering on Chemical Ionization Mass Spectrometry (CIMS) Measurements of GasPhase Sulfuric Acid. Atmos. Chem. Phys. 2011, 11, 3007-3019.

(21) Spartan '14; Wavefunction Inc: Irvine CA, 2014.

(22) Dolg, M; Stoll, H.; Savin, A.; and Preuss, H. Energy-Adjusted Pseudopotentials For the Rare Earth Elements. Theor. Chim. Acta. 1989, 75, 173-194.

(23) Dolg, M.; Stoll, H.; and Preuss, H. A Combination of Quasirelativistic Pseudopotential and Ligand Field Calculations For Lanthanoid Compounds. Theor. Chim. Acta. 1993, $85,441-450$.

(24) Perdew, J. P.; Burke, K.; and Ernzerhof, M. Generalized Gradient Approximation Made Simple. Phys. Rev. Lett. 1996, 77, 3865-3868.

(25) Fuentealba, P.; Preuss, H.; Stoll, H.; and Szentpaly, L. v. A Proper Account of Core- 
Polarization With Pseudopotentials - Single Valence-Electron Alkali Compounds. Chem. Phys. Lett. 1982, 89, 418-422.

(26) Frisch, M. J.; Trucks, G. W.; Schlegel, H. B.; Scuseria, G. E.; Robb, M. A.; Cheeseman, J. R.; Scalmani, G.; Barone, V.; Mennuci, B.; Petersson, G. A.; et al. Gaussian 09. Revision D.01, Gaussian, Inc., Wallingford CT 2009.

(27) Rogachev, A. Y. and Hoffmann, R. Iodine $\left(\mathrm{I}_{2}\right)$ as a Janus-Faced Ligand in Organometallics. J. Am. Chem. Soc. 2013, 135, 3262-3275.

(28) McAllister, L. J.; Bruce, D. W.; and Karadakov, P. B. Quantum Chemical Investigation of Attractive Non-Covalent Interactions between Halomethanes and Rare Gases. J. Phys. Chem. A 2012, 43, 10621-10628.

(29) Forni, A.; Rendine, S.; Pieraccini, S.; and Sironi, M. Solvent Effect on Halogen Bonding: The Case of the I. . O Interaction. Journal of Molecular Graphics and Modelling 2012, 38, 31-39.

(30) Peterson, K. A.; Shepler, B. C.; Figgen, D.; and Stoll H. On the Spectroscopic and Thermochemical Properties of $\mathrm{ClO}, \mathrm{BrO}, \mathrm{IO}$, and Their Anions, J. Phys. Chem. A 2006, 110, 13877.

(31) Feller, D. The Role of Databases in Support of Computational Chemistry Calculations. J. Comp. Chem. 1996, 13, 1571-1586.

(32) Schuchardt, K. L.; Didier, B. T.; Elsethagen, T.; Sun, L.; Gurumoorthi, V.; Chase, J.; Li, J.; and Windus, T. L. Basis Set Exchange: A Community Database for Computational Sciences. J. Chem. Inf. Model 2007, 47, 1045-1052.

(33) Riplinger, C. and Neese, F. An Efficient and Near Linear Scaling Pair Natural Orbital Based Local Coupled Cluster Method. J. Chem. Phys. 2013, 138, 034106. 
(34) Neese, F. The ORCA Program System. Wiley Interdiscip. Rev. Comput. Mol. Sci. 2012, 2, $73-78$.

(35) Riplinger, C.; Hansen, A.; and Neese, F. Natural Triple Excitations in Local Coupled Cluster Calculations With Pair Natural Orbitals. J. Chem. Phys. 2013, 139, 134101.

(36) Werner, H.-J.; Knowles, P. J.; Knizia, G.; Manby, F. R.; Schütz, M.; Celani, P.; Györffy, W.; Kats, D.; Korona, T.; Lindh, R.; et al. MOLPRO, version 2015.1, a package of ab initio programs; 2015; see http://www.molpro.net.

(37) Robertson, S. H.; Glowacki, D. R.; Liang, C.-H.; Morley, C.; Shannon, R.; Blitz, M.; Seakins, P. W.; and Pilling, M. J. MESMER (Master Equation Solver for MultiEnergy Well Reactions), an Object Oriented C++ Program Implementing Master Equation Methods for Gas Phase Reactions With Arbitrary Multiple Wells. 20082013. http://sourceforge.net/projects/mesmer.

(38) Bartis, J. T. and Widom, B. Stochastic Models of the Interconversion of Three or More Chemical Species. J. Chem. Phys. 1974, 60, 3474-3482.

(39) Robertson, S. H.; Pilling, M. J.; Jitariu, L. C.; and Hillier, I. H. Master Equation Methods for Multiple Well Systems: Applications to the 1-,2-pentyl system. Phys. Chem. Chem. Phys. 2007, 9, 4085-4097.

(40) Winiberg, F. A.; Dillon, T. J.; Orr, S. C.; Groß, C. B.; Bejan, I.; Brumby, C. A.; Evans, M. J.; Smith, S. C.; Heard, D. E.; and Seakins, P. W. Direct Measurements of OH and Other Product Yields from the $\mathrm{HO}_{2}+\mathrm{CH}_{3} \mathrm{C}(\mathrm{O}) \mathrm{O}_{2}$ Reaction. Atmos. Chem. Phys. 2016, 16, 4023-4042.

(41) Vereecken, L. and Francisco, J. S. Theoretical Studies of Atmospheric Reaction Mechanisms in the Troposphere. Chem. Soc. Rev. 2012, 41, 6259-6293. 
(42) Epstein, S. A. and Donahue, N. M. Ozonolysis of Cyclic Alkenes as Surrogates for Biogenic Terpenes: Primary Ozonide Formation and Decomposition. J. Phys. Chem. A 2010, 114, 7509-7515.

(43) Johnson, D. and Marston, G. The Gas-Phase Ozonolysis of Unsaturated Volatile Organic Compounds in the Troposphere. Chem. Soc. Rev. 2008, 37, 699-716.

(44) Hyttinen, N.; Rissanen, M. P.; and Kurtén, T. Computational Comparison of Acetate and Nitrate Chemical Ionization of Highly Oxidized Cyclohexene Ozonolysis Intermediates and Products. J. Phys. Chem. 2017, 121, 2172-2179. 


\section{TOC Graphic}

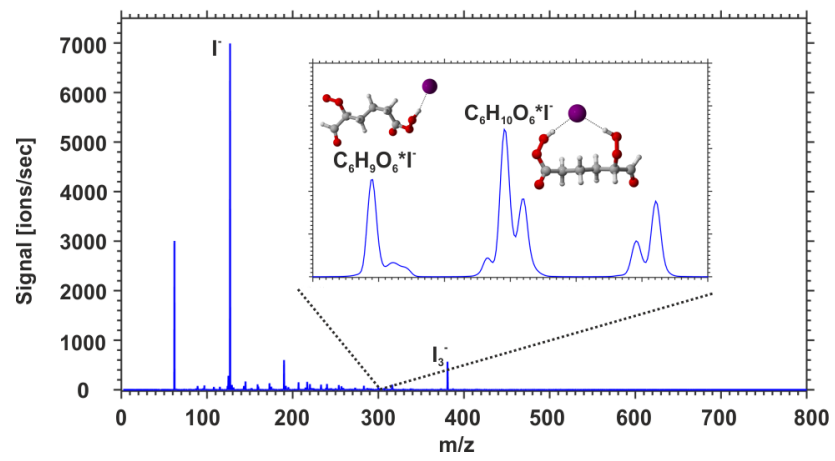

